\title{
LA IMAGEN DE SANTA FE (GRANADA) EN LA SILLERÍA DEL CORO BAJO DE LA CATEDRAL DE TOLEDO ${ }^{1}$
}

\author{
POR \\ LUIS JOSÉ GARCÍA PULIDO \\ $\mathrm{y}$ \\ ANTONIO ORIHUELA UZAL \\ Escuela de Estudios Árabes (Granada). CSIC
}

\begin{abstract}
Las representaciones iconográficas de una ciudad son siempre un valioso testimonio que, cotejado y completado con otros documentos, permiten aproximarse con mayor fidelidad a la morfología y estructura urbana de la misma en un determinado momento histórico. De Santa Fe se ha conservado sólo una imagen de excepcional valor que permite conocer su fisonomía en el momento de su fundación en 1491: un tablero de la sillería del coro bajo de la Catedral de Toledo. En este artículo se demuestra que dicho relieve, atribuido erróneamente hasta ahora al cerco de Málaga, representa en realidad al Real de la Vega y al Real de Santa Fe, con la ciudad de Granada al fondo. La información contenida en esta imagen aporta datos reveladores sobre la nueva ciudad y concuerda con los testimonios documentales contemporáneos y con otras representaciones gráficas de siglos posteriores. rallas.

Palabras clave: Santa Fe; Iconografía; Catedral de Toledo; Guerra de Granada; Reyes Católicos; Mu-

The iconographic representations of a city are always a valuable testimony which, when compared and completed with other documents, permit a more reliable approximation to the morphology and urban structure of a city at a given historical moment. In the case of Santa Fe only one image of exceptional importance has been preserved, revealing its appearance at the time of its foundation in 1491: a panel from the lower choir stalls of Toledo Cathedral. The authors demonstrate that this relief, until now erroneously thought to represent the siege of Malaga, actually shows the Real de la Vega and the Real de Santa Fe, with the city of Granada in the background. The information contained in this image provides revealing data concerning the new city and coincides with contemporary documentary testimonies as well as with other later graphic representations.
\end{abstract}

Key words: Santa Fe; Iconography; Toledo Cathedral; War of Granada; Ferdinand and Isabel; Walls.

\footnotetext{
' Este artículo forma parte de un estudio más amplio en torno a las defensas de Santa Fe en su momento fundacional. Veáse García Pulido, Luis José y Orihuela Uzal, Antonio. Nuevas aportaciones sobre las murallas y el sistema defensivo de Santa Fe (Granada). (En prensa).
} 


\section{Las Representaciones iconográficas de Santa Fe (Granada)}

El Grupo de Investigación de Arquitectura Hispanomusulmana de la Escuela de Estudios Árabes de Granada (Consejo Superior de Investigaciones Científicas) ${ }^{2}$ viene realizando el estudio y análisis de las ciudades enclavadas en el antiguo reino de Granada, en particular en lo referente a sus sistemas de fortificación. En este sentido, la documentación gráfica conservada y la planimetría histórica de una ciudad constituye un elemento clave para este propósito.

El punto de arranque de nuestra investigación lo supuso un importante hallazgo, la nueva adscripción del tema al que alude uno de los tableros del coro bajo de la Catedral de Toledo, obra estudiada por Juan de Mata Carriazo y Arroquía y publicada inicialmente en 1927, bajo el título Los relieves de la Guerra de Granada en la sillería del coro de la Catedral de Toledo ${ }^{3}$.

Inexplicablemente, el tablero en el que se encuentran nítidamente representados los Reales de Santa Fe y de la Vega ${ }^{4}$, con Granada al fondo en un segundo plano (Fig. 1), es identificado por este investigador «acaso por primera vez, como episodio del cerco de Málaga». Para justificarlo desarrolla ampliamente todo un corpus de argumentaciones que intentan demostrar algo que a todas luces es insostenible y, al confundir el Real de Santa Fe con un arrabal de la Málaga islámica, llega incluso a afirmar que «entre los edificios de este arrabal sobresale una espadaña con campana, que es grave impropiedad en plaza de musulmanes» ${ }^{5}$. Por su parte, la ciudad que se ve al fondo es identificada como el Alcázar de Málaga con el Castillo de Gibralfaro en lo alto, sin reparar en que esta representación no es sino una miniatura del tablero que alude a la rendición de Granada, en el que, entre otros elementos, se representan los recintos amurallados de la Medina, el Albayzín y la Alhambra. Como cabría esperar, estos dos tableros ${ }^{6}$ se encuentran en la posición de honor del coro bajo, a ambos lados de la escalera que sube a la silla presidida por el Arzobispo: quedando el de Granada a su derecha y el de Santa Fe a su izquierda, respetando un acertado protocolo.

${ }^{2}$ Los autores desean manifestar su agradecimiento a las siguientes personas:

- A D. Ángel Fernández Avidad, Dr. Arquitecto y profesor de Urbanística en la E.T.S.A. de Granada, por facilitarnos el acceso a su tesis doctoral inédita, titulada Granada: una estructura de un espacio metropolitano. A D. Miguel Ángel Fernández Aparicio, Dr. Arquitecto, por permitirnos consultar su tesis doctoral titulada Santa Fe. Modelo urbano, que en el momento de nuestra toma de datos se encontraba en fase de publicación. A D. David Cabrera Manzano, Arquitecto.

- A Dña. María Luisa Roger Corral, encargada del Archivo Histórico del Ayuntamiento de Santa Fe, quien desde la biblioteca del Instituto de América-Centro Cultural «Damián Bayón» amablemente nos aportó toda la documentación que estaba en sus manos.

- Al Sr. Deán de la Santa Iglesia Catedral Primada de Toledo, y al Sr. Párroco de la Iglesia de la Encarnación de Santa Fe (antigua Colegiata).

- Al profesor D. Vitor Manuel Guimaraes Verissimo Serrão, Director del Instituto de Historia da Arte da Facultade de Letras da Universidade de Lisboa. A D. Joaquim Oliveira Caetano, director del Museu de Évora. A D. José Luis Porfirio, director del Museu Nacional de Arte Antiga de Lisboa. A Dña. Dulce Helena Pires Borges, directora del Museu da Guarda. A D. Agostinho Ribeiro, director del Museu de Lamego. A D. Pompeyo Martín, Comisario del Centro de Coordinación de Bibliotecas de Segovia.

- A Dña. Mariana Kalaitzidou y a Dña. Mayte Penelas Meléndez.

${ }^{3}$ Archivo Español de Arte y Arqueología, 7, pp. 19-70, reeditado por la Universidad de Granada en 1985 con fotografías de Oronoz y prólogo de Antonio Domínguez Ortiz. Carriazo y Arroquía, Juan de Mata. Los relieves de la guerra de Granada en la sillería del coro de la Catedral de Toledo. Granada, 1985. Tablero número 28, p. 68. El relieve al que nos referimos aparece además como portada de esta edición.

${ }^{4}$ En tiempos de los Reyes Católicos se denominó Real de Santa Fe al campamento fortificado que posteriormente dio lugar a la ciudad del mismo nombre, mientras que el Real de la Vega fue el campamento de campaña, de construcción más rápida y efímera, en el que se levantaron tiendas, pabellones y enramadas protegidas por una empalizada de madera, fosos inundados por las acequias y terraplenes de tierra.

${ }^{5}$ Carriazo y Arroquía, Juan de Mata. Los relieves de la guerra de Granada en la sillería del coro de la Catedral de Toledo. Granada, 1985. p. 68.

${ }^{6}$ Tableros que en el estudio de Juan de Mata Carriazo están identificados con los números 27 y 28 para Granada y Santa Fe respectivamente.

AEA, LXXVII, 2004, 307, pp. 247 a 266 

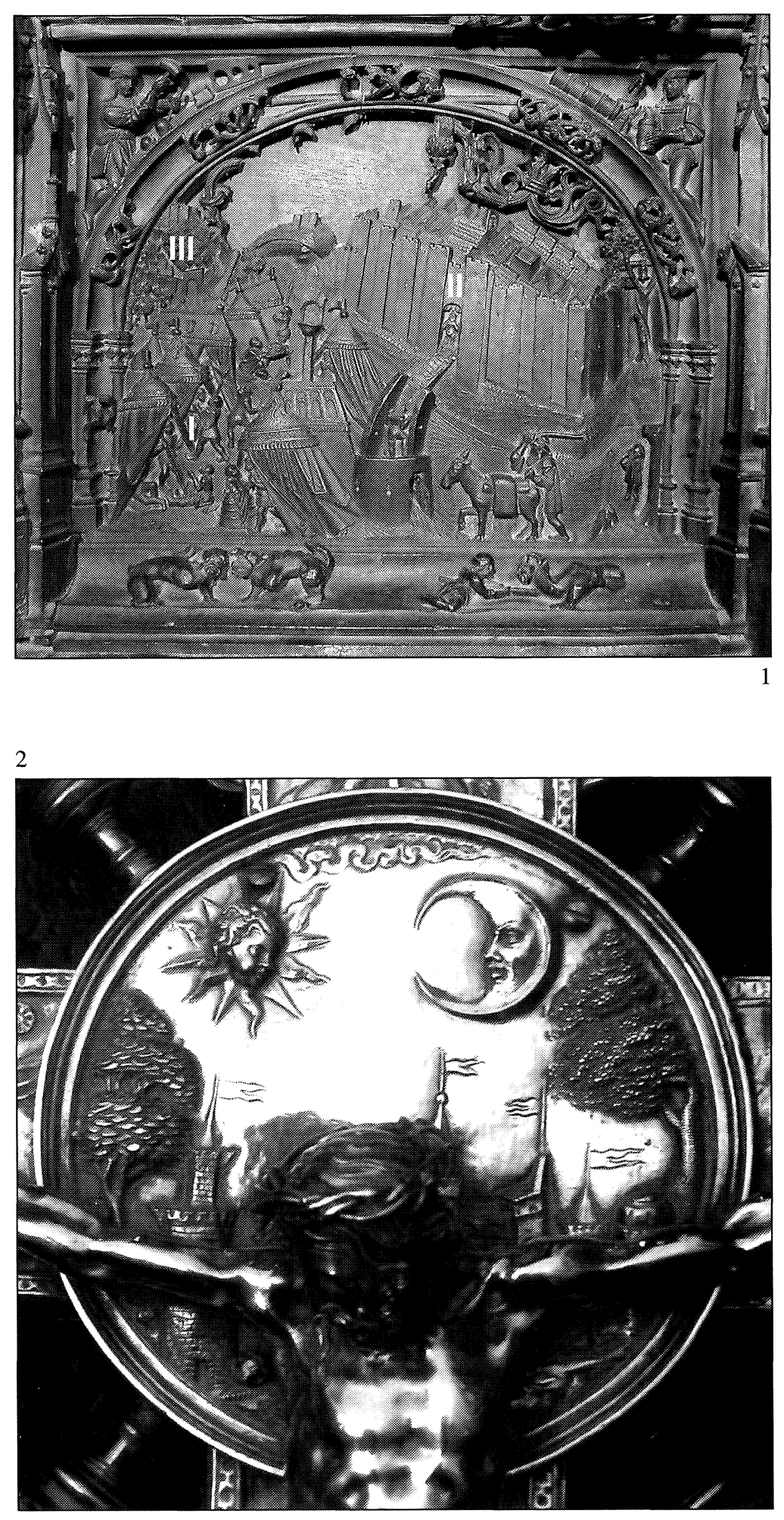

Fig. 1. Tablero de la sillería del coro bajo de la Catedral de Toledo donde se representan el Real de la Vega (I), el Real de Santa Fe (II) y la ciudad de Granada (III). Fig. 2. Cruz de plata repujada conservada en la Iglesia Parroquial de Santa Fe. Detalle de la ciudad representada detrás del crucificado. 
Por tanto, no es de extrañar que, como afirma Carriazo, este relieve sea «por todos conceptos, una de las piezas mejores de la serie». Contemplándolo detalladamente resulta admirable la profusión de detalles y matices que contiene, alejados de la monotonía y convencionalidad con que son representadas las fortificaciones talladas en los restantes tableros. Esto pudiera indicarnos que, o bien el autor del tablero conoció directamente la forma y estructura de Santa Fe, o bien el promotor de la obra quiso hacer hincapié en que la escena representada estuviese lo más cerca posible de la realidad. Por otra parte, la información contenida en el tablero es tanto más interesante por ser su representación coetánea al episodio que pretende inmortalizar, lo que le otorga mayor credibilidad.

La sillería del coro bajo está realizada en estilo gótico y fue comenzada en 1489, en pleno fervor de la Guerra de Granada. La encargó el arzobispo don Pedro González de Mendoza, Cardenal de España, quien hizo decorar los tableros del respaldo con escenas de rendición de plazas fuertes que habían sido conquistadas a los nazaríes, a muchas de las cuales había asistido en persona ${ }^{7}$.

Las cincuenta y dos sillas del coro bajo con sus respectivos tableros, cuyo espacio libre mide $56 \mathrm{cms}$ de ancho por $37 \mathrm{cms}$ de alto ${ }^{8}$, se hicieron en tres partes:

I) Las veinte primeras sillas (correspondientes al lado de la Epístola) fueron concertadas con «maestre Rodrigo, entallador» en $1489^{9}$ y se refieren a ciudades conquistadas hasta ese mismo año. Como es lógico comienzan con la toma de Alhama en 1482, hecho que ha venido siendo considerado como el inicio de la etapa final de la Guerra de Granada.

II) En diversas fechas, desde el 1 de enero de 1493, recibió maestre Rodrigo distintas cantidades a cuenta de las segundas veinte sillas, las del lado del Evangelio. En noviembre de 1493 se comprometió a dar por terminadas las 40 sillas para fin de febrero de 1494, y asentarlas para Pascua de Resurrección ${ }^{10}$. En ellas se representan episodios de la guerra referidos a las campañas de 1488 y 1489.

III) El sábado 10 de enero de 1495 se avienen las 12 sillas del frente del coro, que faltaban por hacer ${ }^{11}$. Entre ellas se encuentran los tableros que representan el sitio y la toma de Granada, punto final de la guerra, junto a otros episodios de la contienda comprendidos entre 1483 y 1490, que el arzobispo González de Mendoza debió de considerar dignos de ser representados en última instancia. Por tanto, la coetaneidad con los acontecimientos de Santa Fe representados, que ocuparon los últimos ocho meses de 1491, es más que notable.

El viajero germano Jerónimo Münzer, quien entró en Toledo el 14 de enero de 1495 tras haber visitado el Reino de Granada en septiembre del año anterior, se interesó por el coro de la Catedral escribiendo: "Las sillas del coro son muchas y han sido labradas recientemente

\footnotetext{
${ }^{7}$ Carriazo y Arroquía, Juan de Mata. Los relieves de la guerra de Granada en la sillería del coro de la Catedral de Toledo. Granada, 1985. pp. 15-16.

${ }^{8}$ Carriazo y Arroquía, Juan de Mata. Los relieves de la guerra de Granada en la sillería del coro de la Catedral de Toledo. Granada, 1985. p. 22.

${ }^{9}$ Zarco Del Valle, Manuel Ramón. Datos documentales para la historia del arte español: II, Documentos de la Catedral de Toledo; colección formada en los años 1869-74 y donada al Centro de Estudios Históricos en 1914 por Manuel R. Zarco del Valle. Madrid, 1916. Tomo I, pp. 18-20. Citado por Carriazo y Arroquía, Juan de Mata. Los relieves de la guerra de Granada en la sillería del coro de la Catedral de Toledo. Granada, 1985. p. 17.

${ }^{10}$ Zarco Del Valle, Manuel Ramón. Datos documentales para la historia del arte español: II, Documentos de la Catedral de Toledo; colección formada en los años 1869-74 y donada al Centro de Estudios Históricos en 1914 por Manuel R. Zarco del Valle. Madrid, 1916. Tomo I, pp. 18-20. Citado por Carriazo y Arroquía, Juan de Mata. Los relieves de la guerra de Granada en la sillería del coro de la Catedral de Toledo. Granada, 1985. p. 18.

${ }^{11}$ Zarco del Valle, Manuel Ramón. Datos documentales para la historia del arte español: II, Documentos de la Catedral de Toledo; colección formada en los años 1869-74 y donada al Centro de Estudios Históricos en 1914 por Manuel R. Zarco del Valle. Madrid, 1916. Tomo I, pp. 18-20. Citado por Carriazo y Arroquía, Juan de Mata. Los relieves de la guerra de Granada en la sillería del coro de la Catedral de Toledo. Granada, 1985. p. 18.
}

$A E A, \mathrm{LXXVII}, 2004,307$, pp. 247 a 266 

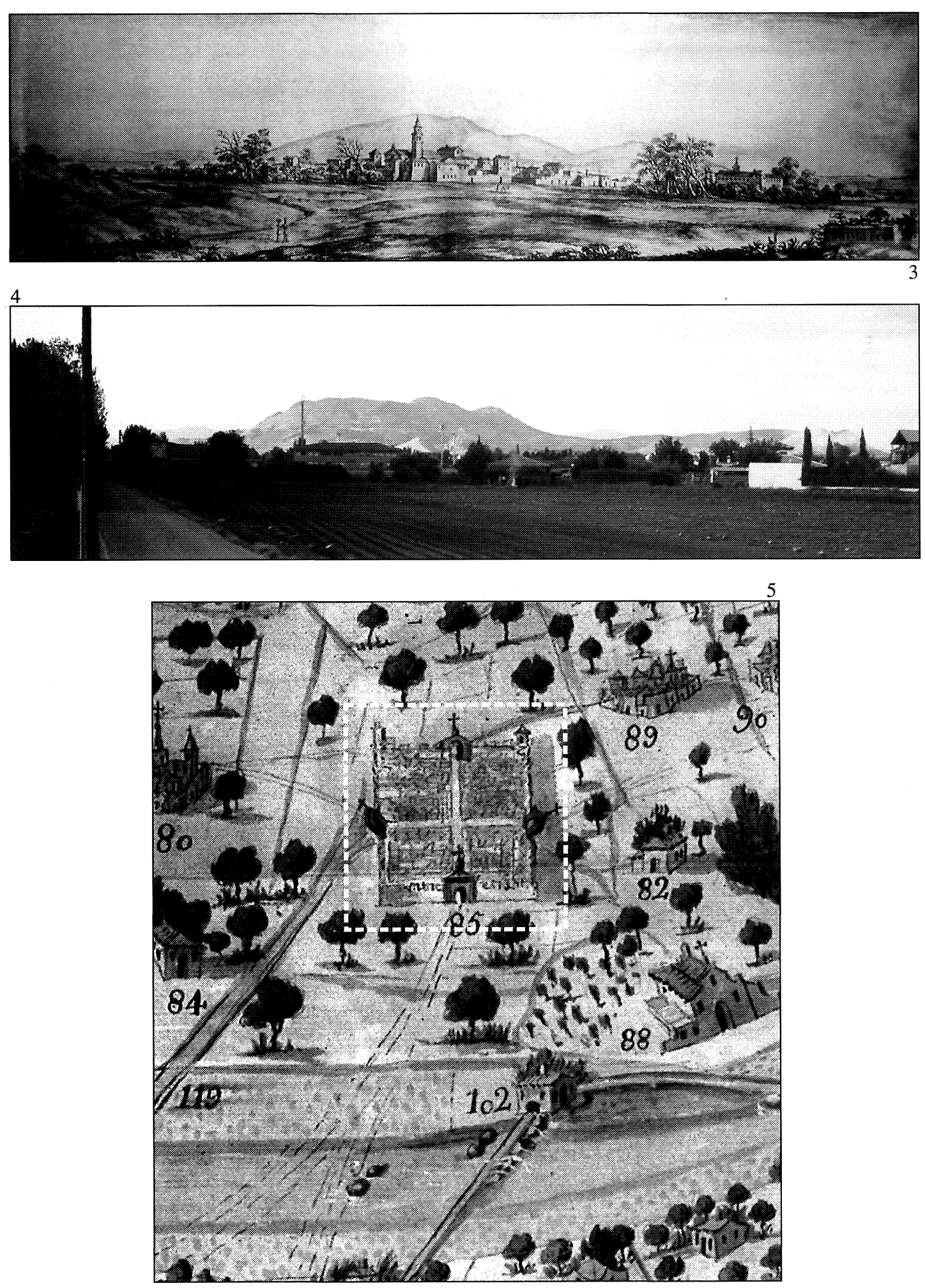

Fig. 3. Vista de Santa Fe desde el suroeste dibujada por Pier María Baldi en 1668.

Fig. 4. Vista actual de Santa Fe desde el Camino de Santa Teresa, al suroeste de la ciudad.

Fig. 5. Plano del diseño del Río Genil dibujado por Thomas Ferrer y rotulado por José Toxar (1751). Detalle de la representación de Santa Fe vista desde el norte. Reeditado por el Ayuntamiento de Granada, 2000. 
por uno de la Baja Alemania. En cada silla está muy bien esculpido un triunfo de ciudad o fortaleza de Granada, que casi parece poner ante los ojos la guerra granadina» ${ }^{12}$. Este testimonio, avalado por la objetividad y precisión con que acostumbraba a describir este médico todo aquello que le impresionaba en sus viajes, nos da una idea del magnífico documento histórico que supone el testimonio gráfico contenido en este tablero.

Debemos decir que esta temprana representación de Santa Fe no fue la única que existió con motivo de su fundación. Si un detenido análisis e interpretación de este tablero nos aporta cuantiosa información, más debiera haber contenido el lienzo que por motivos propagandísticos fue enviado a la Corte portuguesa en agosto de 1491, coincidiendo con la desdichada y accidental muerte del Príncipe don Alonso de Portugal, yerno de los Reyes Católicos. Así nos lo refirió el tesorero de la Reina Isabel, Gonzalo de Baeza: «Por una nomina de su Alteza, firmada y asentada, fecha 13-VIII del [di]cho año [1491] (...): Que costo pintar la villa de Santa Fe para enbiar a Portogal, 1.500 mrs., con el lienço en que se pinto» ${ }^{13}$. Desgraciadamente, la búsqueda de este testimonio gráfico ha sido infructuosa por nuestra parte ${ }^{14}$.

El segundo testimonio gráfico de Santa Fe en importancia debió de constituirlo otra representación de la ciudad promovida por los Reyes Católicos, en este caso, y al igual que la del tablero de la Catedral toledana, con vocación tridimensional. Como símbolo de su devoción, los monarcas dedicaron la primera plata que vino de América para hacer una peana al Lígnum Crucis que habían regalado al convento de la Santa Cruz de Segovia ${ }^{15}$. Y es que, «entre otros dones ofreció el vencido rey [Boabdil] a los vencedores una gran reliquia de la cruz en que murió el Redentor del mundo, con tradición de que estaba en poder de sus ascendientes desde que sujetaron a España. (...). Para adorno, mandaron labrar de plata cendrada, dicen que fué la primera que se trajo de Indias, un modelo de la ciudad de Santa Fé, con sus muros, puertas $y$ torreones que sirve de peana o calvario a una cruz de la misma plata (...)» ${ }^{16}$. A finales del siglo XIX este pedestal estaba ya desaparecido pues, según unos, fue expoliado por los franceses durante la Guerra de la Independencia y, según otros, se fundió para sufragar los gastos de reedificación del convento después del incendio que sufrió en 1809. Por el contrario, la cruz de la reliquia sí se conservó, estando en ese momento en poder de los dominicos ${ }^{17}$. Desde entonces, nada se sabe acerca del paradero del pedestal, como hemos podido corroborar tras ponernos en contacto con estudiosos sobre los bienes muebles de los edificios religiosos segovianos.

La tercera representación coetánea de la conquista de Granada en la que teníamos depositadas nuestras esperanzas formaba parte de los motivos decorativos de una cruz procesional de plata repujada, conservada en la Iglesia Parroquial de Santa Fe (Fig. 2). Esta cruz fue realiza-

\footnotetext{
${ }^{12}$ Münzer, Jerónimo. Viaje por España y Portugal en los años 1494 y 1495 . Versión del latín, noticia preliminar y notas por Julio Puyol. Madrid, 1924. pp. 117 y 248.

${ }^{13}$ De la Torre, Antonio y Alsina, Engracia. Cuentas de Gonzalo de Baeza, tesorero de Isabel la Católica. Madrid, 1955. Tomo I: $1477-1491$. pp. 405-406.

${ }^{14}$ Trasladamos nuestra búsqueda a Portugal, sin embargo nada se sabe del lienzo en los museos portugueses. D. Joaquím Oliveira Caetano, director del Museu de Évora - quien se encuentra en estos momentos estudiando una temática similar para el caso de las ciudades portuguesas - nos comunicó que no se conocía representación alguna de Santa Fe conservada en las colecciones y archivos de su país. Por otra parte, el profesor D. Vitor Manuel Guimaraes Verissimo Serrão, Director del Instituto de Historia da Arte da Facultade de Letras da Universidade de Lisboa, quien muy amablemente se interesó por el tema, tampoco consiguió dar con el paradero del lienzo, por lo que es muy probable que éste se perdiera hace tiempo.

${ }^{15}$ Navamuel, Fray J. Cueva de Santo Domingo. Madrid, 1752. p. 31. Citado por LLorente Tabanera, María Josefa. El Convento de Santa Cruz. Segovia, 1961. p. 16.

${ }^{16}$ Colmenares, D. Historia de Segovia, $2^{\mathrm{a}}$ Edición, 1640. p. 356. Citado por LLorente Tabanera, María Josefa. El Convento de Santa Cruz. Segovia, 1961. p. 17.

${ }^{17}$ Lecea, C. de. La cueva de Santo Domingo de Guzmán. Segovia, 1895. p. 55. Citado por LLorente Tabanera, Maria Josefa. El Convento de Santa Cruz. Segovia, 1961. p. 17.
}

$A E A$, LXXVII, 2004, 307, pp. 247 a 266 
da a finales del siglo Xvi, para sustituir a la primitiva de oro, que los Reyes Católicos donaron a la Iglesia Colegial de Santa Fe, aunque fue trasladada en 1549 a la Catedral de Granada ${ }^{18}$. Esta vez sí pudimos acceder a la copia de plata existente en Santa $\mathrm{Fe}$, en la que tras el crucificado del anverso aparece una ciudad murada. Sin embargo, lejos de lo que cabría esperar, no se pretendió representar la fisonomía de Santa Fe, sino que se talló una ciudad imaginaria al uso, cuyos torreones de cubiertas cónicas nos trasladan a una tradición constructiva muy alejada de nuestras latitudes.

Tras estas primeras imágenes que se remontaban a la génesis de

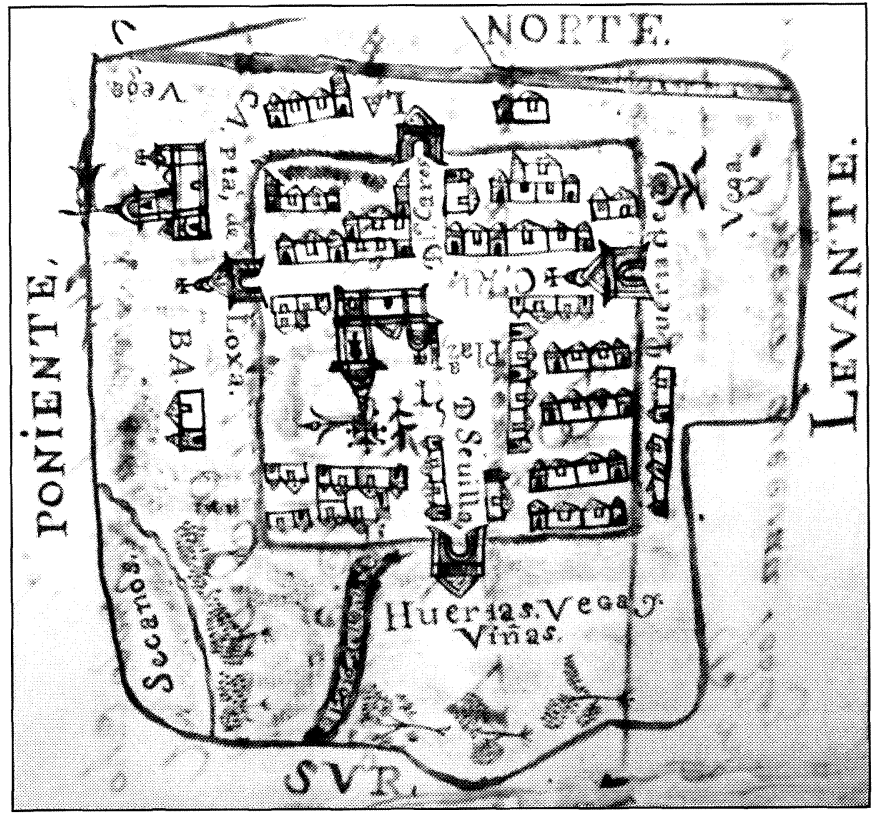

Fig. 6. Representación de Santa Fe en el Catastro del Marqués de la Ensenada (1754). Santa Fe, y de las cuales hasta la fecha sólo nos ha llegado una, habrá que esperar más de 250 años hasta que la ciudad vuelva a ser representada. Con motivo del viaje que Cosme de Médicis realizó por España y Portugal, este noble italiano pasó con su séquito por Santa Fe y el Soto de Roma el 19 de diciembre de 1668. El dibujante que lo acompañaba, Pier Maria Baldi, tomó entonces una vista de Santa Fe desde el suroeste de la ciudad (Fig. 3), en un punto cercano al actual camino de Santa Teresa, que en gran medida mantiene el trazado del camino que llegaba a la Puerta de Sevilla. La orientación de este grabado ha venido siendo adscrita a un punto de vista septentrional a la ciudad ${ }^{19}$. Sin embargo, el fondo de perspectiva, en el que a grandes rasgos se esboza la silueta de Sierra Elvira, ubicada al norte de Santa Fe, sitúa ineludiblemente la vista en un punto meridional a la misma (Fig. 4). Con ello, la torre de la Iglesia Colegial existente en ese momento estaría adosada a la misma por su lado meridional, según se aprecia en el dibujo.

Del siglo XviII se conservan tres representaciones generales de la ciudad. La primera se incluye en el plano del diseño del Río Genil dibujado por Thomas Ferrer y rotulado por José Toxar, que se remonta a 1751 (Fig. 5). En él aparece claramente la forma cuadrangular de Santa $\mathrm{Fe}$, con todo su perímetro amurallado, sus cuatro puertas y algunas torres de esquina, pero sin cavas. No obstante, esta situación idealizada no debía de ser la que realmente tuviese la ciudad en esa época, pues Cosme de Médicis ya lamentaba en 1668 que a la ciudad «(...) le falte gran parte de la muralla y la zanja esté casi toda llena» ${ }^{20}$. Este plano, perteneciente a la colección de la Sra. Viuda de Molina Fajardo, ha sido reeditado en el año 2000 por el Ayuntamiento de Granada con motivo de la conmemoración del Quinto Centenario de su constitución.

En 1754 se realizó una nueva representación gráfica de Santa Fe (Fig. 6), junto al resto de los pueblos y ciudades de Granada, todas ellas contenidas en el Catastro promovido por el Mar-

\footnotetext{
${ }^{18}$ Lapresa Molina, Eladio. Santafe: Historia de una ciudad del siglo xv. Granada, 1979. pp. 57-58.

${ }^{19}$ Espinosa Cabezas, Ángel. Santa Fe. Aproximaciones geográfico-históricas. Maracena (Granada), 1995. pp. $182-183$.

${ }^{20}$ Cosme de Médicis. Viaje por España y Portugal (1668-1669). Ilustraciones de Pier Maria Baldi. Edición y notas por Angel Sánchez Rivero y Angela Mariutti de Sánchez Rivero. Madrid, 1933, p. 212. Agradecemos a Mariana Kalaitzidou la traducción que nos hizo de la parte referente a Santa Fe, originalmente en italiano.
} 


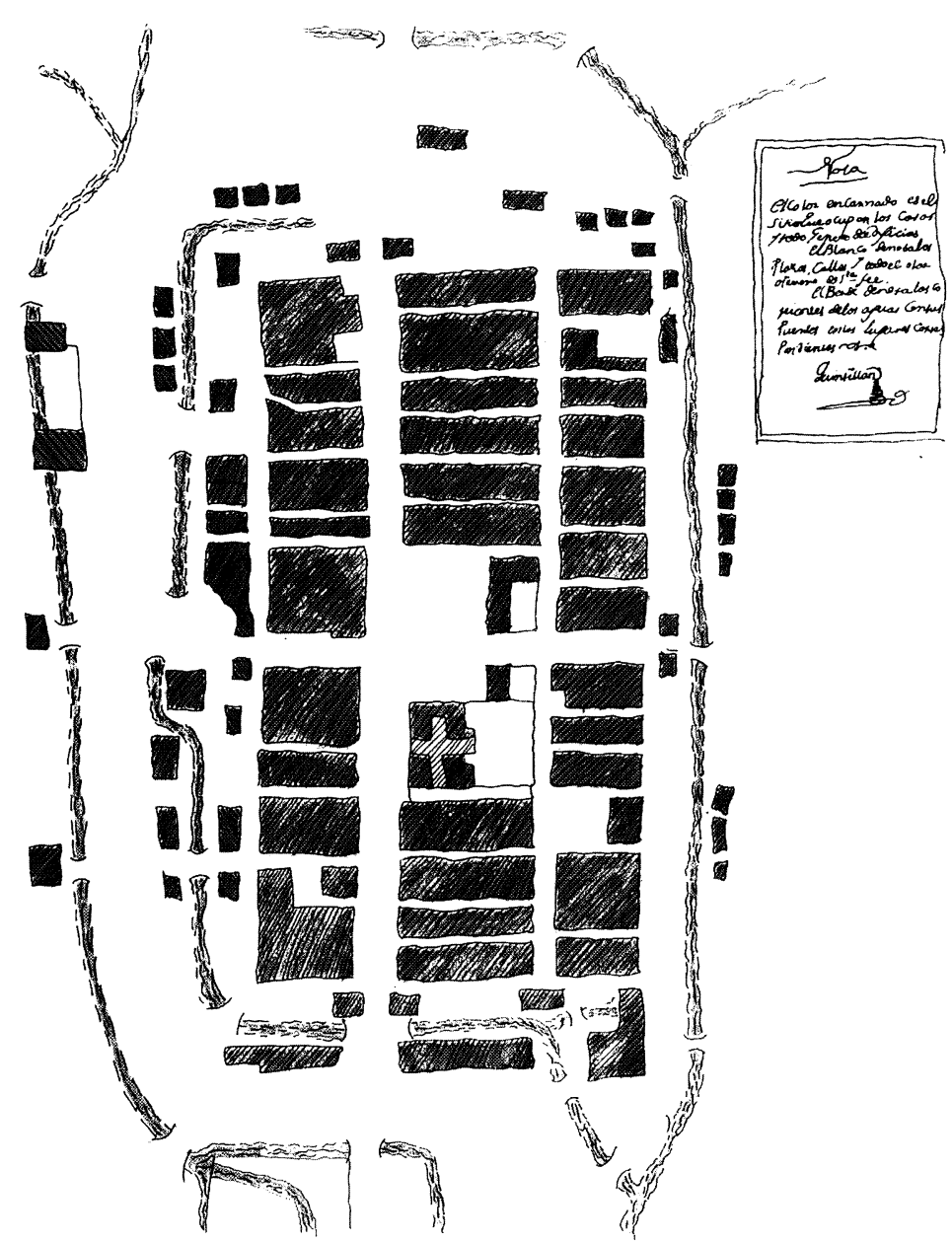

Fig. 7. Plano de Santa Fe de Francisco Quintillán (1780). Este plano formó parte del proyecto que Domingo A. Lois Monteagudo realizó en 1777 para el desagüe y saneamiento de la cava norte. qués de la Ensenada. Sin embargo, la imagen naïf de la ciudad resulta sumamente esquemática, pues en estos croquis de apoyo al catastro se daba más importancia a los bienes de la ciudades contenidos en su término municipal que a los elementos morfológicos de éstas, que sólo se esbozaban en sus rasgos más eminentes (puertas con sus nombres, Iglesia, Convento de los Agustinos extramuros y traza cuadrangular en el caso de Santa $\mathrm{Fe}$ ) para poder ser identificadas con facilidad.

Finalmente, cabe señalar el famoso plano de Francisco Quintillán de 1780 (Fig. 7), que formó parte del proyecto que Domingo A. Lois Monteagudo realizó en 1777 para el desagüe y saneamiento de la cava norte ${ }^{21}$. Este plano es el primero conservado en el que se dibujó la planta de la ciudad. Sin embargo, no se esbozó ningún paño de mura-

\section{El tablero del Coro bajo de la Catedral de Toledo en el que se representó Santa Fe}

Este tablero, al igual que el resto, contiene una escena principal enmarcada por un doble arco carpanel, que representa el sitio o la toma de una ciudad, mientras que en las enjutas se labraron motivos costumbristas o alegóricos. En este caso, en la enjuta izquierda (Fig. 8) aparece un operario tallando bolas para los artefactos pirobalísticos de la época (lombarda, ribadoquín...), a partir de dados de piedra. Para ajustar el diámetro del proyectil al del cañón ${ }^{23}$ se contaba con un rudimentario calibrador de madera donde encajar las bolas. En la enjuta dere-

\footnotetext{
${ }^{21}$ Aristondo Akarregi, Salvador. «El arquitecto Domingo Antonio Lois Monteagudo». Fiestas de San Agustín. Santa Fe (Granada), 2001, p. 11.

${ }^{22}$ Espinosa Cabezas, Ángel. Santa Fe. Aproximaciones geográfico-históricas. Maracena (Granada), 1995. p. 123.

${ }^{23}$ Ésta era una de las cuestiones técnicas peor resueltas en estos primeros ingenios artilleros, de ahí que, entre otros motivos, con posterioridad se sustituyeran las balas de piedra por las de fundición de acero.
} 


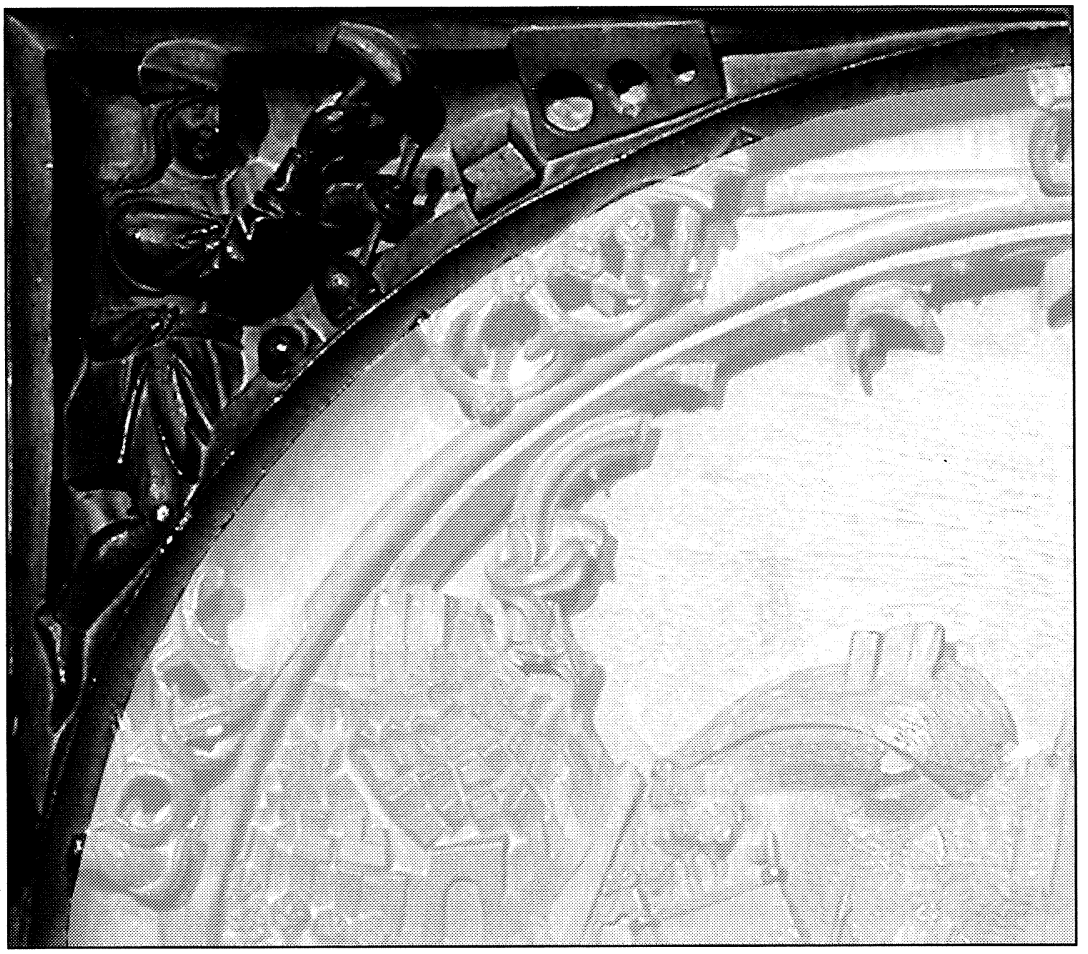

8

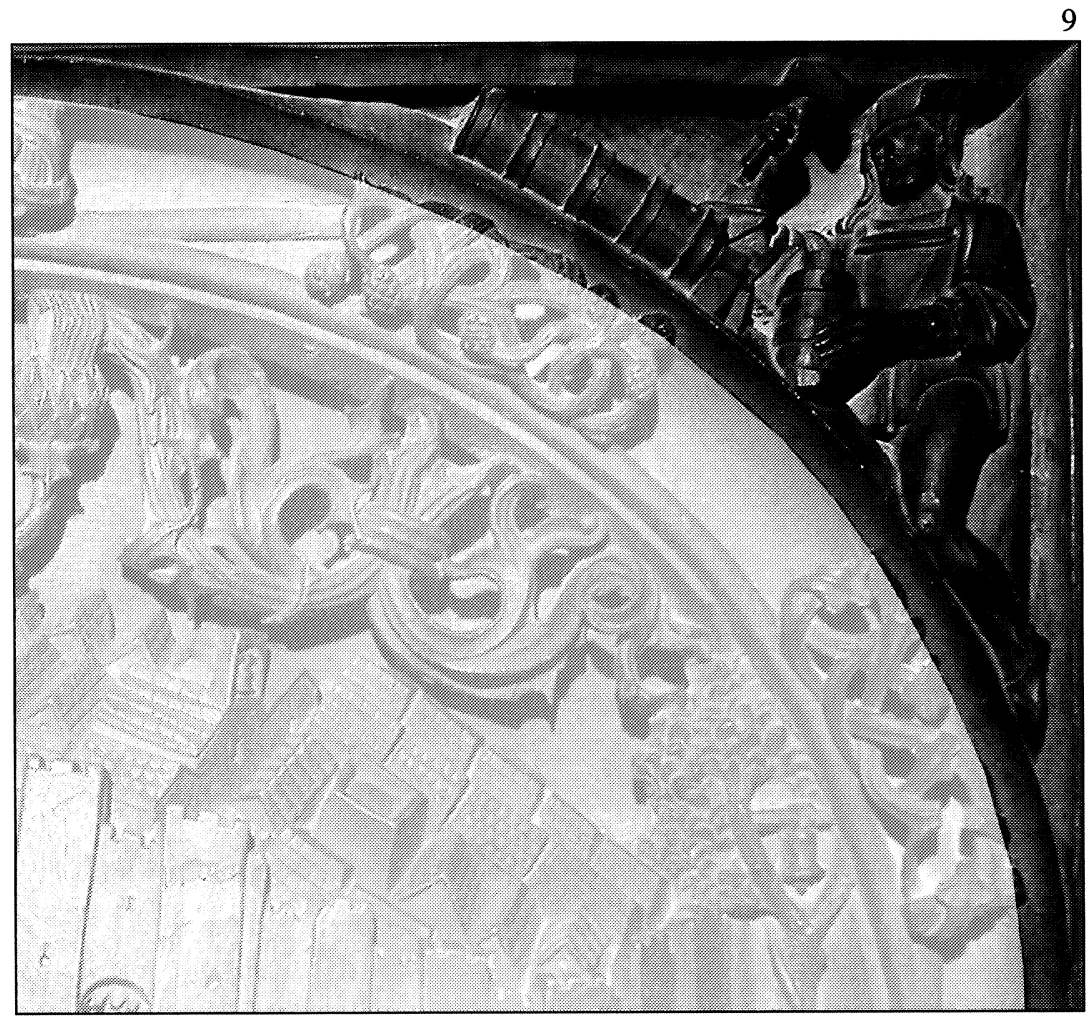

Fig. 8. Detalle de la enjuta izquierda del tablero de la sillería del coro bajo de la Catedral de Toledo en el que se representó Santa Fe.

Fig. 9. Detalle de la enjuta derecha del tablero de la sillería del coro bajo de la Catedral de

Toledo en el que se representó Santa Fe. 
cha (Fig. 9) un artillero carga la recámara de una lombarda, golpeando el taco con un martillo para comprimir la pólvora que en la deflagración habrá de impulsar el proyectil pétreo. Es de especial interés esta talla por ilustrar las piezas de que estaban compuestas estas lombardas (caña y recámara, cinchadas con aros metálicos), así como el proceso de carga de las mismas. La vestimenta de los artilleros también aparece magníficamente representada.

El hecho de que este tablero sea el único que contiene en las enjutas del arco semejantes escenas bélicas debió de estar motivado por el reconocimiento que los propios castellanos y aragoneses otorgaban a la artillería, como uno de los aspectos desequilibrantes que les permitió llevar a buen término la Guerra de Granada. En este sentido disentimos de la explicación dada por Juan de Mata Carriazo, quien mantiene que las enjutas de este arco aluden directamente al uso de la pólvora en el cerco de Málaga. Bien es cierto que Granada no fue acosada con fuego artillero (el campamento cristiano estaba muy alejado de ella), aunque sí que debieron de estar presentes la piezas de artillería en el Real de la Vega y las murallas de Santa Fe, desempeñando una labor defensiva, conforme aconsejaba la práctica de milicia a que aluden los cronistas de los Reyes Católicos.

\subsection{El Real de la Vega}

La escena representada bajo el arco contiene tres ámbitos bien diferenciados. En la parte inferior izquierda aparece una vista ligeramente elevada del Real de la Vega (Fig. 10), o más bien del ordenado corazón del Real, donde se ubicaban las ostentosas tiendas reales y nobiliarias, puesto que «(...) el rey e la reyna e el príncipe e infantas e damas e señoras tenían sus tiendas e possadas en lo más fuerte e seguro de real (...)» ${ }^{24}$, mientras que el resto del ejército «(...) procuró de hacer dentro de aquel sitio sus choças y ramadas (...)» ${ }^{25}$. Aparecen en el tablero (Fig. 11) seis tiendas alfaneques ${ }^{26}$ (A) ricamente bordadas, una de las cuales contiene un escudo heráldico con corona (A'). Probablemente representa la tienda perteneciente a Fernando el Católico, quien quizás podría identificarse con la figura saliente que entabla conversación con un soldado. Dos tiendas más son de tipo marquesina (B y B'), con planta rectangular y cubierta a cuatro aguas. Una de ellas, la más cercana a la del Rey, contiene dos escudos en su cubierta (B'). Bien podría tratarse de una de las grandes tiendas o pabellones aportados por la reina Isabel en cada temporada bélica. Así nos lo refirió el cronista real Fernando del Pulgar al relatarnos la campaña de 1484: «(...) para curar los feridos e dolientes la reina embiaba siempre a los reales seis tiendas grandes e las camas e ropas necesarias para los feridos y enfermos y enviaba físicos e cirujanos e medicinas e onbres que los sirviesen, (...), y estas tiendas con todo este aparejo se llamava en los reales el Hospital de la Reyna» ${ }^{27}$. Tras ella sale apresuradamente una dama portando una bandeja con lo que podrían ser paños de curación o alimentos.

\footnotetext{
${ }^{24}$ Bernáldez, Andrés. Memorias del reinado de los Reyes Católicos que escribía el bachiller Andrés Bernáldez, Cura de Los Palacios. Edición y estudio por Manuel Gómez-Moreno y Juan de Mata Carriazo y Arroquía. Madrid, 1962. Capítulos C y CI. pp. 224-232. Documento que reproduce Peinado Santaella, Rafael Gerardo. La fundación de Santa Fe (1491-1520). Granada, 1995. p. 326.

${ }^{25}$ Santa Cruz, Alonso de. Crónica de los Reyes Católicos. Edición y estudio por Juan de Mata Carriazo y Arroquía. Sevilla, 1951. Tomo I (1491-1504), capítulos I y II, pp. 31 y 35-38. Documento que reproduce Peinado Santaella, Rafael Gerardo. La fundación de Santa Fe (1491-1520). Granada, 1995. pp. 330-331.

${ }^{26}$ Tienda o pabellón de campaña, generalmente circular y con cubierta cónica.

${ }^{27}$ Pulgar, Fernando del (ca. 1430-ca. 1493). Crónica de los Reyes Católicos por su secretario Fernando del Pulgar. Edición y estudio por Juan de Mata Carriazo y Arroquía. Madrid, 1943. Tomo II, Guerra de Granada. Cap CLX. p. 120. Documento citado por Lapresa Molina, Eladio. Santafe: Historia de una ciudad del siglo xv. Granada, 1979. p. 19.
}

$A E A$, LXXVII, 2004, 307, pp. 247 a 266 


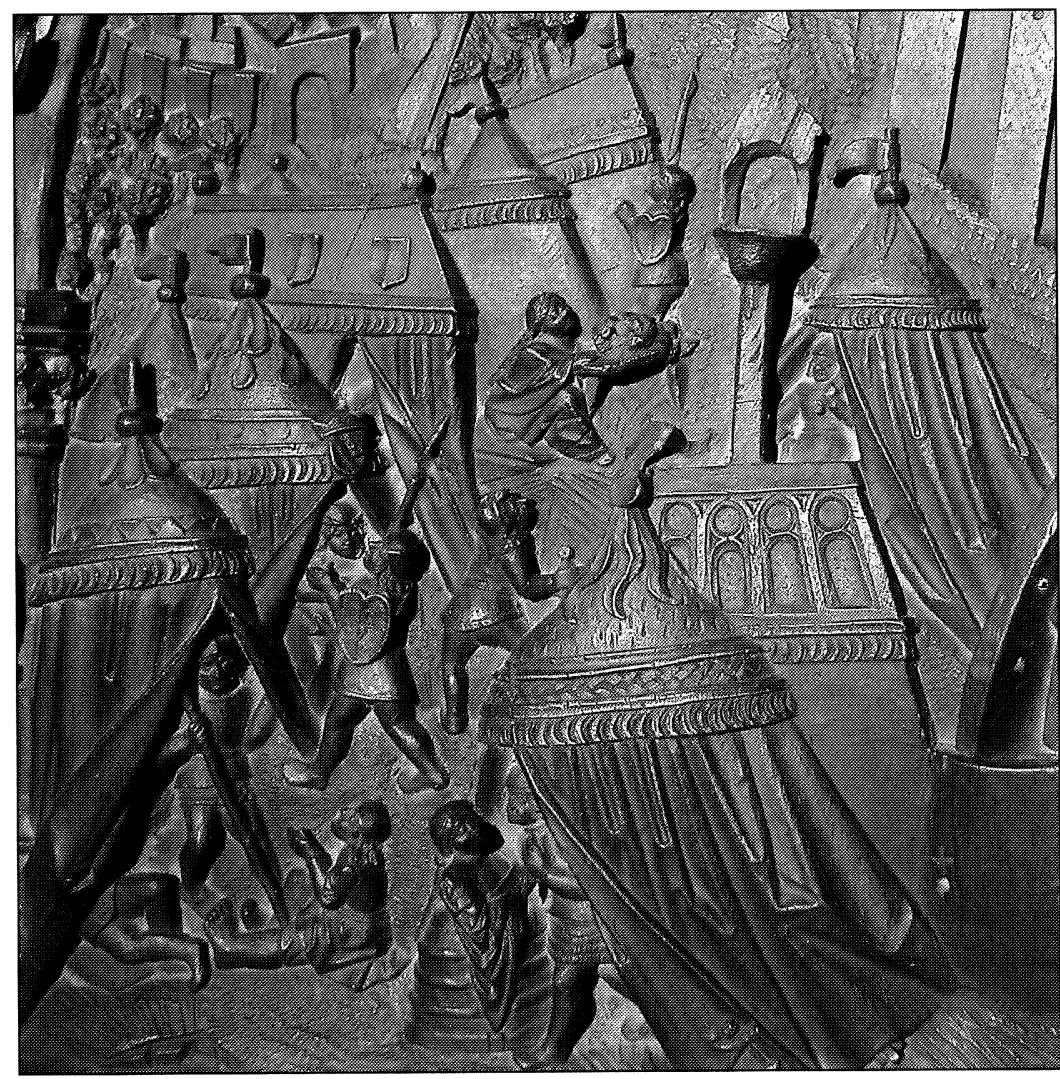

10

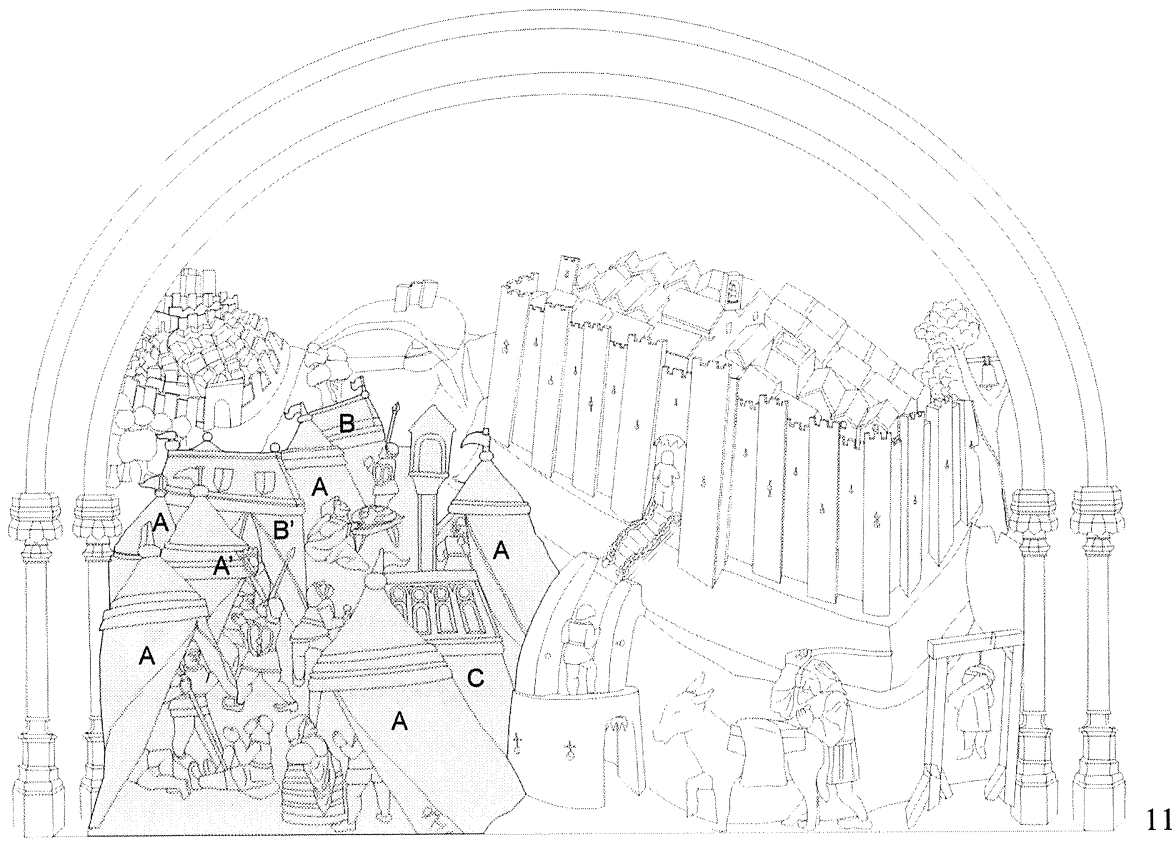

Fig. 10. Detalle del Real de la Vega en el tablero de la sillería del coro bajo de la Catedral de Toledo en el que se representó Santa Fe.

Fig: 11. El Real de la Vega en el tablero de la sillería del coro bajo de la Catedral de Toledo en el que se representó Santa Fe, redibujado por los autores. 
Entre las tiendas, un extraño elemento destaca por su rasgos distintivos (C). Se trata de una construcción con tres cuerpos bien diferenciados: uno inferior, de forma troncopiramidal ${ }^{28}$, una especie de columna o torre muy esbelta como elemento intermedio, y una coronación de todo el conjunto mediante un cobertizo a dos aguas, del que sólo quedan las improntas, por haber sido desprendida la talla del tablero. Creemos haberla identificado gracias al testimonio de Pedro Mártir de Anglería, quien en su carta del 31 de octubre de 1491 dirigida al cardenal Ascanio María Sforza Visconti, relata lo siguiente: «En el campamento, entre las tiendas reales, levantóse una torre de madera, creo que de tres cuerpos, como aposento de los Reyes, desde la cual se dominaba en toda su extensión la llanura» ${ }^{29}$. Esta torre vigía debió de ser utilizada por los Reyes Católicos en su parte inferior como tienda de mando, más que como aposento, pues de las crónicas de la época se deduce que ambos cónyuges descansaban en tiendas diferentes, siendo la de Isabel la lujosa «(...) tienda alfaneque que el marqués de Cádiz avía prestado a la Reina quando vino al real, que era la más jentil pieça y mejor labrada que se pudiera hallar» ${ }^{30}$.

En cuanto a la agitada escena que se observa en el campamento, Juan de Mata Carriazo colige que «Representa un campamento cristiano, en el que se cuentan nueve ricas tiendas de campaña de distinta traza, entre las cuales se lucha confusamente». Esta interpretación debió de ser la que definitivamente le llevó a identificar el tema del tablero como «(...) la salida y ataque al campamento cristiano que hicieron los moros de Málaga el 29 de mayo de 1487 (Palencia, p. 295); o el lunes 28, como dice Valera (p. 251-254)» ${ }^{31}$. Cierto es que la impresión que ofrece la escena es la de una confrontación cuerpo a cuerpo, entre unos personajes que parecen querer entrar en las tiendas nobiliarias y los que de ellas salen aturdidos por la sorpresa. Sin embargo, frente a lo que cuentan los cronistas sobre el cerco de Málaga, del de Granada no relatan que se entablara escaramuza alguna dentro del Real de la Vega (lo que hubiera sido un suceso demasiado importante como para ser obviado por todos ellos), mientras que sí refieren con todo detalle otras gestas bélicas acaecidas en diferentes lugares de la vega granadina. Sin embargo, en el Real de la Vega se produjo un inoportuno acontecimiento que conmocionó y puso en jaque a los sitiadores, hasta el punto de ser relatado por todos los cronistas e historiadores de la época, llegando incluso a quedar retenido en la memoria de las generaciones posteriores como el motivo último por el cual se edificó el Real de Santa Fe: «Acaesçio en el real, un jueves en la noche, catorce dias del mes de jullio, que la reina mandó quitar una vela a una donzella (...). E durmiendo la reina e la mayor parte de la gente del real, dexando los que velavan e rondavan, como quiera que fué, o de la flama de la dicha vela (...) encendió la tienda e alço llamas de fuego, e alcanço el fuego della a otras; e como avía muchas ramadas, encendióse un grand fuego. E como la reina lo sentió, salió fuyendo de la tienda e fuesse a la tienda del rey, que estava ay cerca de la suya (...)» ${ }^{32}, \ll Y$ como este infortunio

\footnotetext{
${ }^{28}$ Esta especie de pabellón parece contar a su vez con dos partes separadas por una franja: una inferior lisa y otra superior, sobre la cual se ubican cuatro ventanales.

${ }^{29}$ Mártir de Anglería, Pedro. Carta, de 31 de octubre de 1491, al cardenal Ascanio María Sforza Visconti. Epistolario. Estudio y traducción por José López de Toro. Madrid, 1953. Tomo I, pp. 165-168. Documento que reproduce Peinado Santaella, Rafael Gerardo. La fundación de Santa Fe (1491-1520). Granada, 1995. p. 333.

${ }^{30}$ Santa Cruz, Alonso de. Crónica de los Reyes Católicos. Edición y estudio por Juan de Mata Carriazo y Arroquía. Sevilla, 1951. Tomo I (1491-1504), capítulos I y II, pp. 31 y 35-38. Documento que reproduce Peinado Santaella, Rafael Gerardo. La fundación de Santa Fe (1491-1520). Granada, 1995. p. 330.

${ }^{31}$ Carriazo y Arroquía, Juan de Mata. Los relieves de la guerra de Granada en la sillería del coro de la Catedral de Toledo. Granada, 1985. p. 68.

${ }^{32}$ Bernáldez, Andrés. Memorias del reinado de los Reyes Católicos que escribía el bachiller Andrés Bernaldez, Cura de Los Palacios. Edición y estudio por Manuel Gómez-Moreno y Juan de Mata Carriazo y Arroquía. Madrid, 1962. Capítulos C y CI, pp. 224-232. Documento que reproduce Peinado Santaella, Rafael Gerardo. La fundación de Santa Fe (1491-1520). Granada, 1995. pp. 326 y 327.
}

$A E A$, LXXVII, 2004, 307, pp. 247 a 266 
tomase a todos al primer sueño, se levantaban como atónitos, corriendo de una parte a otra, no sabiendo de donde les pudiese aver sucedió tanto mal. Y el Rey se levantó en camisa, y tomando las armas salió afuera (...)» ${ }^{33}$. En efecto, si analizamos más detenidamente los atuendos de todos los agitados personajes que deambulan por el Real de la Vega, y los comparamos con la fisonomía de los musulmanes que aparecen en todos los tableros, podemos comprobar que estas figuras representan a soldados, damas y caballeros cristianos. Todos los soldados están enfundados en atuendos militares castellanos: celada ${ }^{34}$, coraza, cota de malla, cinturón y vestimenta corta, muy distintos de las largas túnicas, turbante y barba con que aparecen los musulmanes. La adarga ${ }^{35}$ con borlas que portan dos de ellos, lejos de ser exclusiva de los soldados andalusíes, debió de ser asumida por los castellanos tras el intercambio táctico y armamentístico que supuso la Batalla de la Higueruela $(1431)^{36}$, por lo que la tónica en toda la serie es que se encuentre en manos cristianas ${ }^{37}$, reposando en el hombro si no se entabla batalla, como así ocurre en este tablero. Se pueden observar en la escena soldados durmiendo al raso o a cubierto que se levantan repentinamente, mientras que otras figuras entran en las tiendas para alertar a sus moradores, o simplemente corren despavoridas por el campamento. Debemos decir no obstante, que las llamas del incendio, no aparecen visibles por ningún lado, al menos entre las piezas del tablero que no han saltado ni se han roto. Quizás el autor no quiso añadir más elementos a la escena que desvirtuaran la composición, o bien suponía que el suceso era tan conocido que sería fácilmente reconocible. En este mismo sentido debemos recordar que tanto este tablero como el de Granada no llevan escrito nombre alguno que aluda a la ciudad que representan.

\subsection{El Real de Santa Fe}

A la derecha del tablero aparece tallado con bastante detalle el Real de Santa Fe (Fig. 12). Esta imagen resulta de extraordinaria importancia, pues muchos de los elementos representados en ella han desaparecido en nuestros días, trascendiendo únicamente la transformada morfología urbana del campamento militar primigenio.

Hoy por hoy está más que aceptada la hipótesis de que el Real de Santa Fe comenzó a construirse casi a la par que el Real de la Vega, o una vez estuvo éste estructurado y suficientemente fortificado, no siendo el incendio del 14 de Julio de 1491 la causa última por la que los Reyes Católicos decidieron levantarlo ${ }^{38}$, como la tradición y la historiografía popular han querido mantener, sino el deseo obstinado de los monarcas de dar por concluida la empresa granadina. Así, en el caso de que el cerco se dilatase y hubiese que levantar el Real de la Vega por la llegada del invierno, un contingente de tropas quedaría guarnecido en la ciudad-campa-

\footnotetext{
${ }^{33}$ Santa Cruz, Alonso de. Crónica de los Reyes Católicos. Edición y estudio por Juan de Mata Carriazo y Arroquía. Sevilla, 1951. Tomo I (1491-1504), capítulos I y II, pp. 31 y 35-38. Documento que reproduce Peinado Santaella, Rafael Gerardo. La fundación de Santa Fe (1491-1520). Granada, 1995. p. 330.

${ }^{34}$ Yelmo cincelado con forma esférica que, dejando descubierta la cara, cubría y defendía la parte superior de la cabeza.

${ }^{35}$ Escudo de cuero con forma bivalva, ovalada o acorazonada.

${ }^{36}$ Carriazo y Arroquía, Juan de Mata. Los relieves de la guerra de Granada en la sillería del coro de la Catedral de Toledo. Granada, 1985. pp. 30-31.

${ }^{37}$ Otro tanto ocurre con las tiendas alfaneques o la forma de cabalgar a la jineta, que debieron de pasar de musulmanes a cristianos durante el sinfín de confrontaciones bélicas protagonizadas por ambas facciones con anterioridad a la Guerra de Granada.

${ }^{38}$ Aunque, como resulta lógico, el Real de Santa Fe recibía un vigoroso y necesario impulso edilicio «(...) después de las desgracias que precedieron a la orden de acelerar la construcción de la ciudad (...)». Mártir de Anglería, Pedro. Opus Epistolarum. Alcalá, 1530. Estudio y traducción por José López de Toro. Madrid, 1953. Documento que reproduce Lapresa Molina, Eladio. Santafe: Historia de una ciudad del siglo xv. Granada, 1979. p. 46.
}

AEA, LXXVII, 2004, 307, pp. 247 a 266 


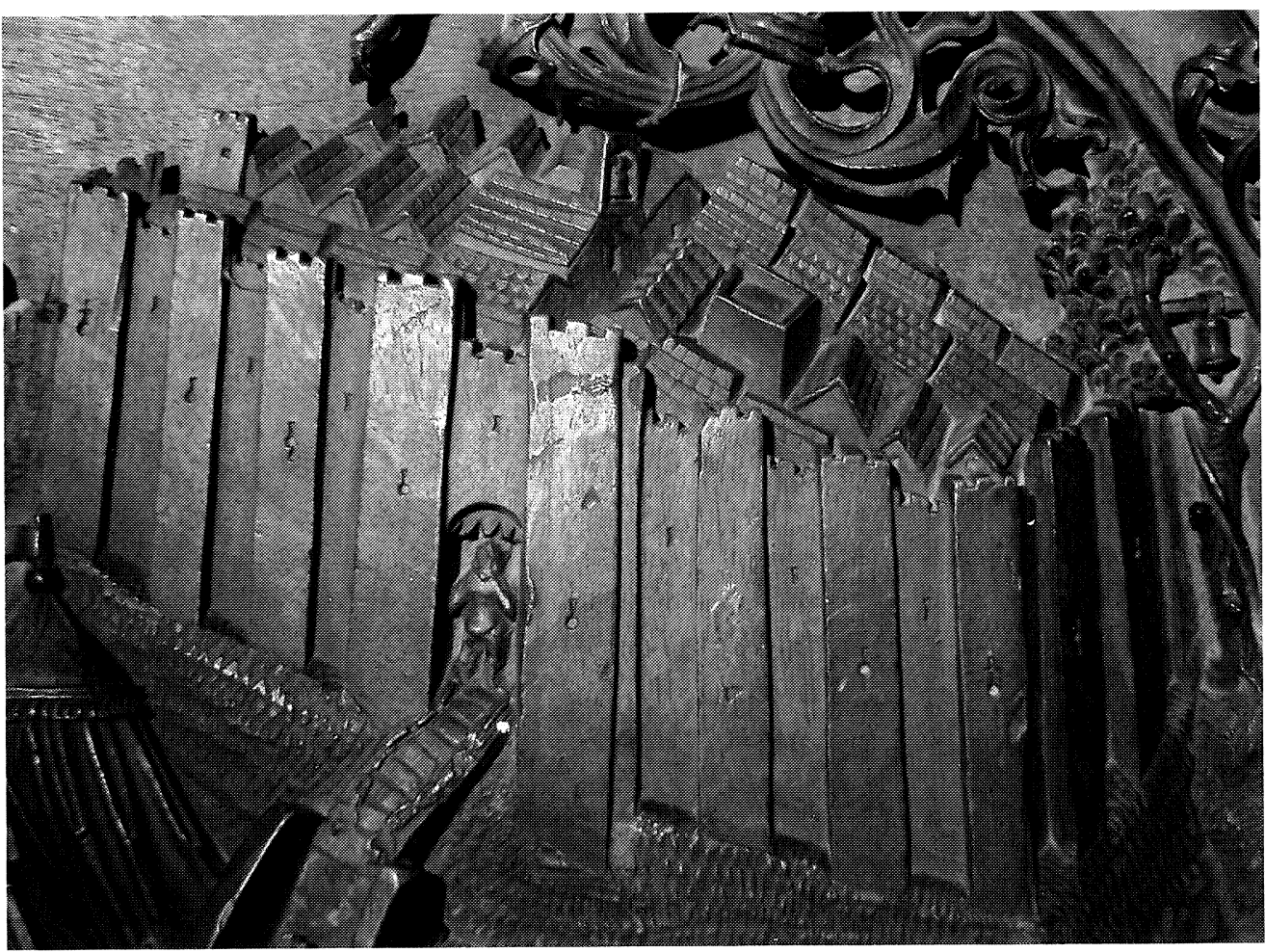

12

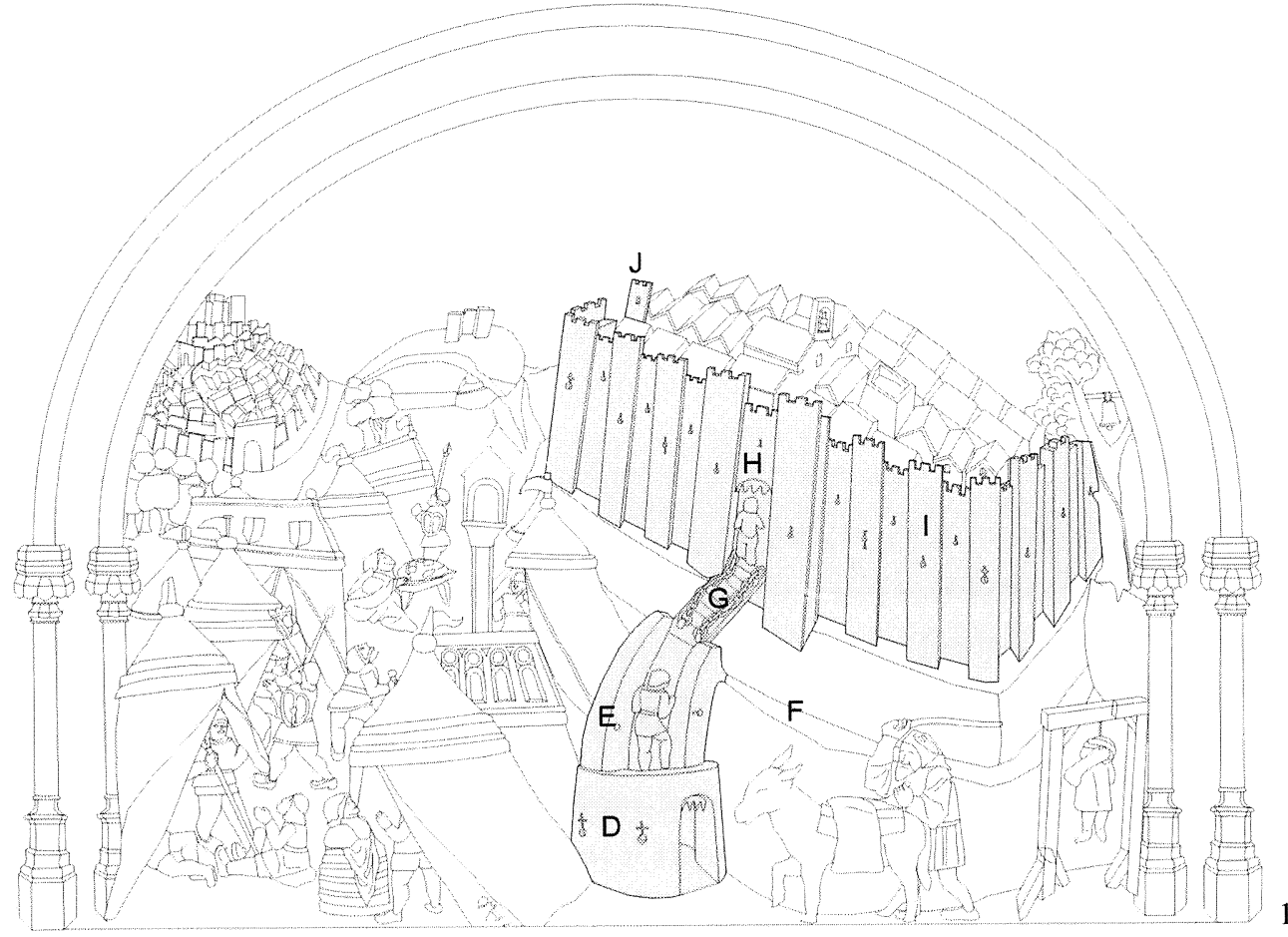

Fig. 12. Detalle del Real de Santa Fe en el tablero de la sillería del coro bajo de la Catedral de Toledo en el que se representó Santa Fe.

Fig. 13. Las defensas del Real de Santa Fe en el tablero de la sillería del coro bajo de la Catedral de Toledo en el que se representó Santa Fe, redibujado por los autores.

AEA, LXXVII, 2004, 307, pp. 247 a 266 
mento para seguir hostigando a los nazaríes. Entre otros cronistas, esta es la razón que nos da Alonso de Palencia: «con propósito de ulterior defensa, se comenzó a construir junto al campamento el simulacro de una ciudad que había de perdurar con el nombre de Santa Fe, mostrando al enemigo que no faltaría en aquella ciudad un ejército escogido de caballería e infantería si en todo el verano no se conseguía el fin deseado (...)» ${ }^{39}$. Con esta operación estratégica, los monarcas cristianos conseguían minar doblemente los postreros ánimos de los granadinos, por cuanto mostraban claramente al enemigo cuán firme era su voluntad de doblegar la capital nazarí, a la vez que realizaban un portentoso alarde del potencial del ejército cristiano, que era capaz de edificar una ciudad en un breve espacio de tiempo ${ }^{40}$. Lo contenido en este tablero vendría a corroborar lo que los documentos escritos narran, pues en él aparecen el Real de la Vega y el de Santa Fe en un mismo momento cronológico, definido por la fecha del incendio del primero de éstos.

Junto al Real de la Vega (Fig. 13) se emplaza un baluarte ${ }^{41}$ circular (D) con dos troneras ${ }^{42}$ visibles de cruz y orbe y arco de entrada con el rastrillo ${ }^{43}$ alzado. Protegido a sus espaldas, un través $^{44}(\mathrm{E})$ sensiblemente curvo ${ }^{45}$ se prolonga hasta la mitad del amplio foso o cava $(\mathrm{F})$, en cuyos antepechos elevados se abren sendas troneras de palo y orbe, y entre los cuales discurre un soldado cristiano. Este través se comunica con la puerta de entrada de la fortaleza mediante un puente levadizo de madera $(\mathrm{G})$ que permite ser izado por medio de dos gruesas cadenas. $\mathrm{Al}$ fondo, otro soldado penetra por la puerta del recinto amurallado $(\mathrm{H})$, puerta que, al igual que la del baluarte, contiene otro rastrillo izado. Con esta imagen cobra especial significación la descripción que hace el anónimo continuador de la Crónica de Pulgar, quien nos relata cómo a los Reyes Católicos «Parescióles cosa muy dificultosa é casi imposible la permanencia del Real, é por este respecto, habido su consejo, mandaron hacer una villa de muy buena cerca é muy buenas cavas, é con muy buenos baluartes é con sus traveses, é todo lo que era más necesario

${ }^{39}$ Palencia, Alonso de. Guerra de Granada. Epístola que, desde Sevilla, escribió Alonso de Palencia, el 8 de enero de 1492, a don Juan Ruiz de Medina, obispo de Astorga, para narrarle los últimos sucesos de la Guerra de Granada y la entrega de la capital (1490-1492). Texto castellano, según la traducción Lapresa Molina, Eladio. Santafe: Historia de una ciudad del siglo xv. Granada, 1979. p. 205.

40 «Fué tal el entusiasmo en el trabajo, que a los ochenta días quedaron terminadas las obras. Se realizaban éstas a espaldas del campamento». Mártir de Anglería, Pedro. Carta, de 31 de octubre de 1491, al cardenal Ascanio María Sforza Visconti. Epistolario. Estudio y traducción por José López de Toro. Madrid, 1953. Tomo I. «(...) de día y de noche, hicieron los muros y torres y cavas y puertas, y otras cosas necesarias; todo dentro de ochenta días. Y así mesmo la población de casas». Santa Cruz, Alonso de. Crónica de los Reyes Católicos. Edición y estudio por Juan de Mata Carriazo y Arroquía. Sevilla, 1951. Tomo I (1491-1504), capítulos I y II, pp. 31 y 35-38. Documentos que reproduce Peinado Santaella, Rafael Gerardo. La fundación de Santa Fe (1491-1520). Granada, 1995. pp. 334 y 331.

${ }^{41} \mathrm{Voz}$ polisémica en sus inicios, en uso desde el último tercio del siglo xv utilizándose para denominar pequeñas fortificaciones artilladas de características indefinidas. Este baluarte a la antigua poco tiene que ver formal y funcionalmente con el polígono irregular generalmente estrellado que sobresale en el encuentro de dos lienzos de muralla y que es propio de la fortificación abaluartada que se desarrolla a partir de la segunda mitad del siglo xvi. La voz baluarte a la que se refieren los cronistas se correspondería con la acepción actual de barbacana, entendiéndose por ésta a la fortificación avanzada y aislada utilizada para defender puertas de plazas o cabezas de puente, y que es atravesada por el camino de acceso, controlándolo. Mora-Figueroa, Luis de. Glosario de arquitectura defensiva medieval. Cádiz, 1994. p. 47.

${ }^{42}$ La tronera es un hueco pequeño, con abocinamiento interior (ensanchamiento en el vano de disparo) y en ocasiones exterior (en la embocadura o salida), abierto en los muros y antepechos para disparar con armas de fuego portátiles o ligeras. Pueden ser de muchos tipos, según la apariencia externa del modelo adoptado, destacando las de cruz y orbe y palo y orbe, que comienzan a generalizarse en la Europa mediterránea a partir de la segunda mitad del siglo xv. Mora-Figueroa, Luis de. Glosario de arquitectura defensiva medieval. Cádiz, 1994. p. 221 y ss.

${ }^{43}$ Pesada reja de madera y/o hierro que se desliza verticalmente entre hendiduras laterales, a modo de compuerta, para poder bloquear rápidamente el pasaje de ingreso a una fortificación. Mora-Figueroa, Luis de. Glosario de arquitectura defensiva medieval. Cádiz, 1994. p. 176.

${ }^{44}$ Muros que unen el baluarte o bastión con la cortina o muro principal de la plaza. Cobos Guerra, Fernando. «Artillería y fortificación ibérica de transición en torno a 1500». Mil anos de fertificações na Península Ibérica e no Magreb (5001500): Actas do Simpósio Internacional sobre Castelos. Lisboa, 2001. p. 690.

${ }^{45}$ Quizás esta curvatura tallada por el autor, pudiese ser un artificio para dar una sensación de perpectiva, con lo que el través podría haber sido recto y perpendicular a la muralla. 


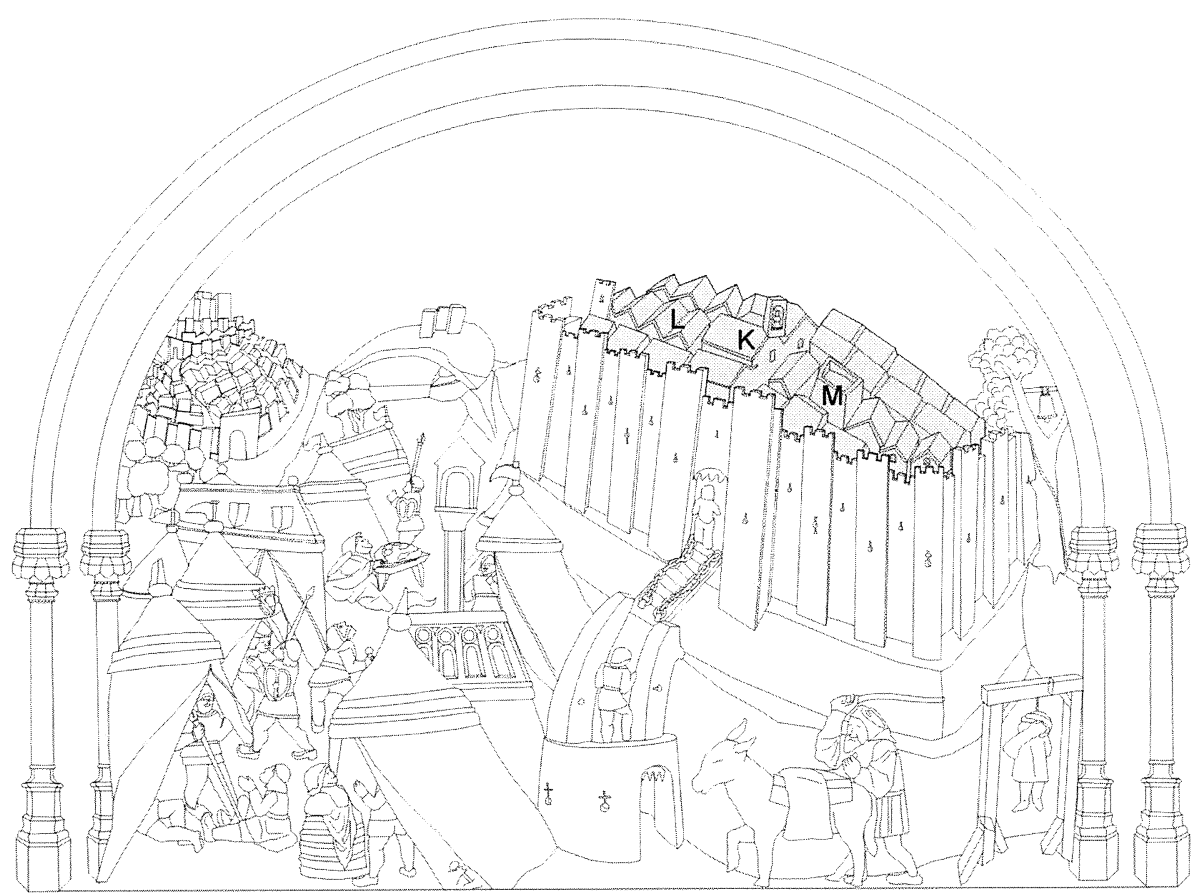

14
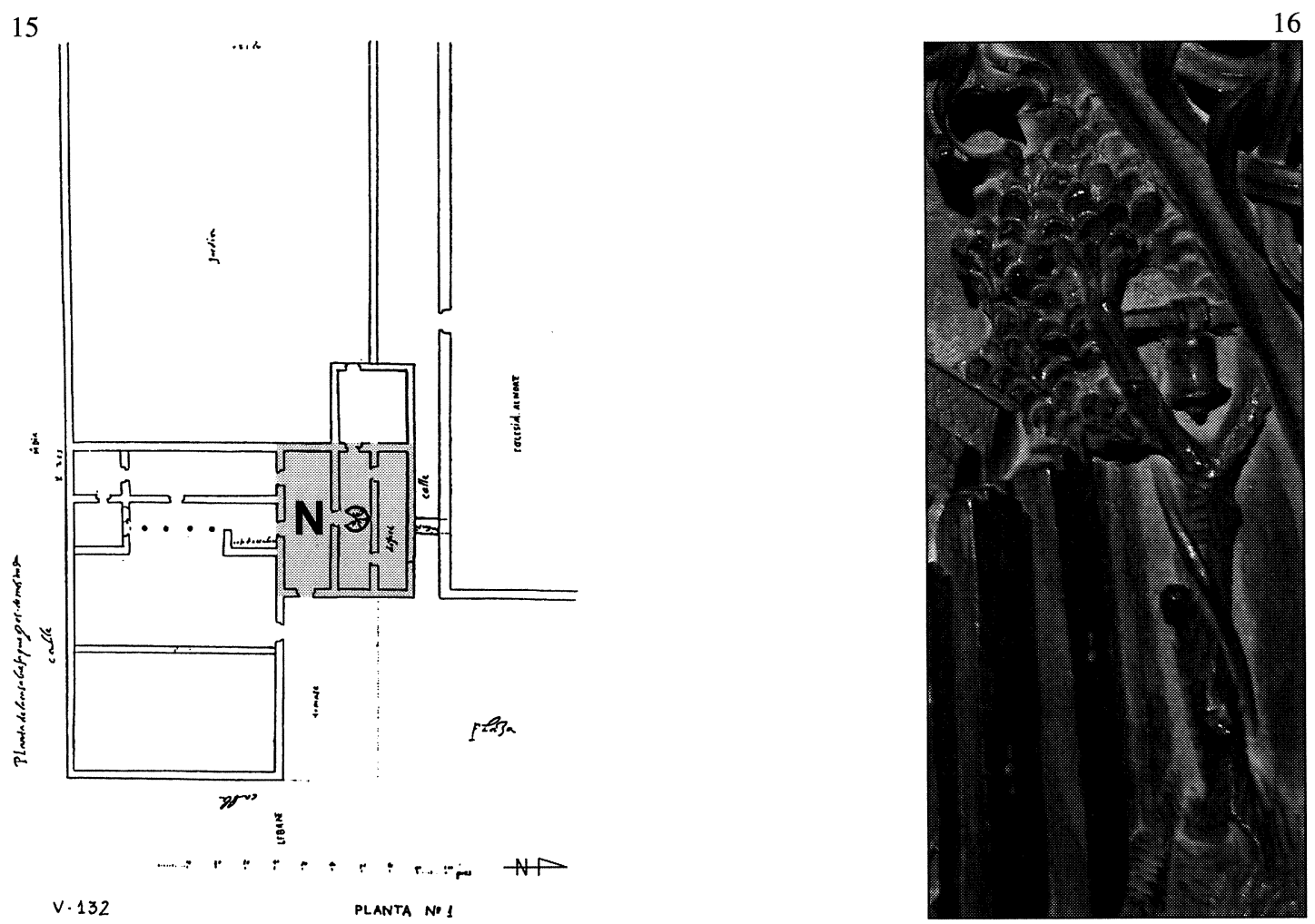

Fig. 14. La ciudad-campamento del Real de Santa Fe en el tablero de la sillería del coro bajo de la Catedral de Toledo en el que se representó Santa $\mathrm{Fe}$, redibujado por los autores.

Fig. 15. Plano de la planta baja de la Casa Real de Santa Fe. Archivo General de Simancas, seción de Mapas, Planos y Dibujos. Signatura V-132.

Fig. 16. Detalle del árbol que sostiene una campana junto al Real de Santa Fe en el tablero de la sillería del coro bajo de la Catedral de Toledo en el que se representó Santa Fe.

$A E A$, LXXVII, 2004, 307, pp. 247 a 266 


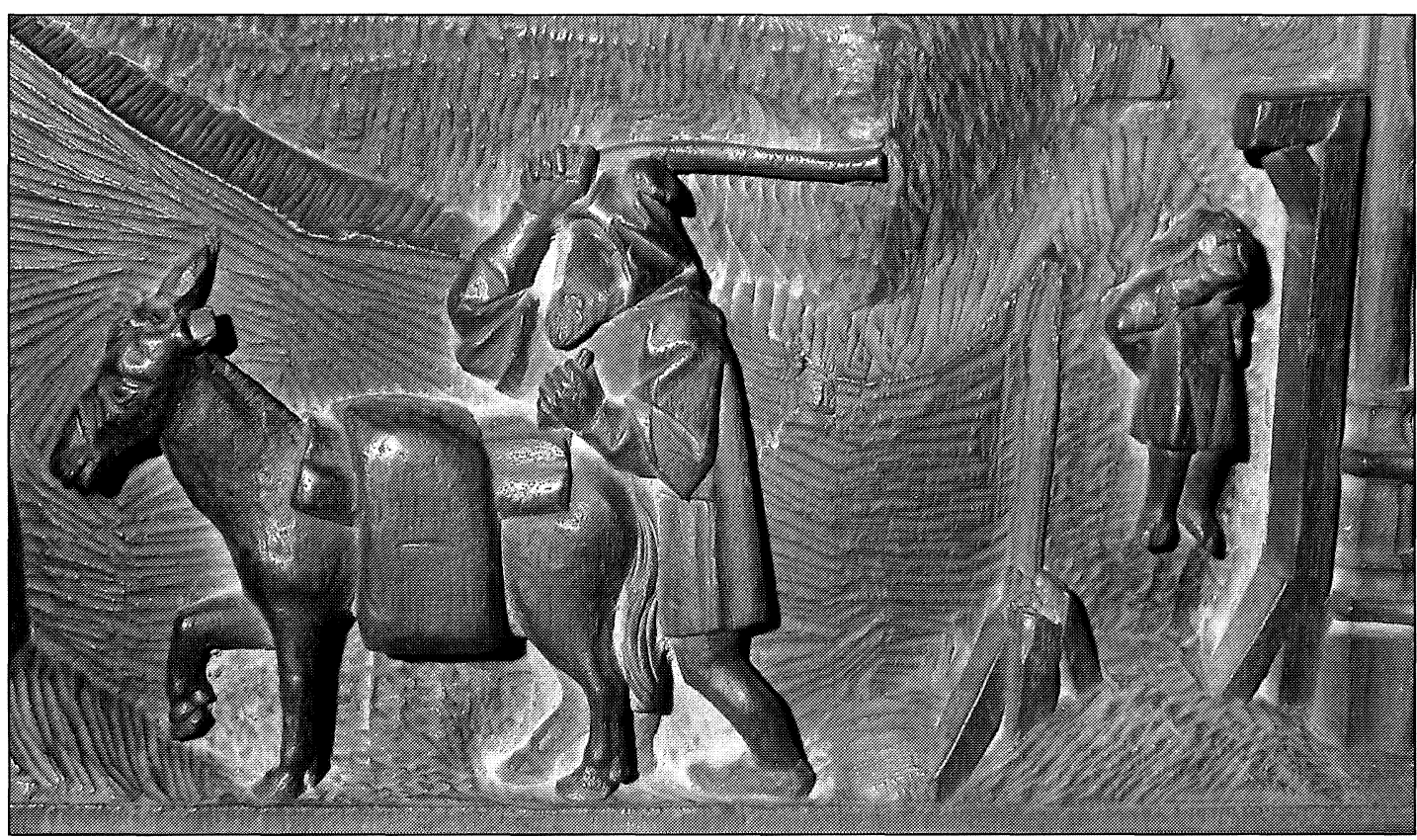

Fig. 17. Detalle de musulmanes en el tablero de la sillería del coro bajo de la Catedral de Toledo en el que se representó Santa Fe. El de la izquierda conduce un burro cargado con alforjas y el de la derecha está ajusticiado en una horca.

para que pudiesen defensar é sostenerse junto al mismo Real é casi dentro en él (...)» ${ }^{46}$. Por su parte, la cerca aparece flanqueada por torreones almenados (I), que tienden a avanzar hasta el cambio de cota donde comienza el profundo foso, «La ciudad (...). Tiene murallas almenadas, fosos, defensas y fuertes torres» nos dirá Pedro Mártir de Anglería ${ }^{47}$. A media altura de cada torreón se abren troneras de palo simple o palo doble y orbe alternadas, siendo de cruz y orbe en los torreones de esquina. A otra cota, ya cercana a las almenas, vuelven a aparecer troneras de palo y orbe que deben de corresponder al adarve de guardia. Orientada hacia Granada, casi en posición de esquina, destaca una torre más esbelta a la manera de atalaya, la famosa Torre de Santiago (J), que ya aparece citada en algunos documentos relativos al reparto de tierras, así como en el primer deslinde del término municipal de Santa $\mathrm{Fe}^{48}$.

Como no podía ser de otro modo, el Real de Santa Fe presenta una estructura ordenada en la que se distinguen dos calles longitudinales que se cruzan con otra transversal (Fig. 14), pues «Su forma es casi rectangular, dejando una plaza en el centro. En cada uno de sus cuatro lados se ha dejado una puerta. (...). Se han levantado edificios con capacidad para acoger a las tropas correspondientes a ellas en el único piso que tienen ${ }^{49}$. En el centro de la plaza se distingue la iglesia (K), de cuya cumbrera arranca una espadaña con una sola campana. Su al-

${ }^{46}$ Continuación de la Crónica de Pulgar por un Anónimo. Editada por Cayetano Rosell. Madrid, 1953. Biblioteca de Autores Españoles, tomo LXX. «Crónica de los Reyes de Castilla», III, pp. 515-516. Documento que reproduce Peinado Santaella, Rafael Gerardo. La fundación de Santa Fe (1491-1520). Granada, 1995. p. 329.

${ }^{47}$ Mártir de Anglería, Pedro. Carta, de 31 de octubre de 1491, al cardenal Ascanio María Sforza Visconti. Epistolario. Estudio y traducción por José López de Toro. Madrid, 1953. Tomo I, pp. 165-168. Documento que reproduce Peinado Santaella, Rafael Gerardo. La fundación de Santa Fe (1491-1520). Granada, 1995. p. 334.

48 "(...) enpeçaron a sacar las suertes dende la primera suerte que esta amojonada mas çercana a la torre de Santyago (...)» Libro de Repartimiento de Santa Fe, 32r. Documento citado por Peinado Santaella, Rafael Gerardo. La fundación de Santa Fe (1491-1520). Granada, 1995. p. 53.

${ }^{49}$ Mártir de Anglería, Pedro. Carta, de 31 de octubre de 1491, al cardenal Ascanio María Sforza Visconti. Epistolario. Estudio y traducción por José López de Toro. Madrid, 1953. Tomo I, pp. 165-168. Documento que reproduce Peinado Santaella, Rafael Gerardo. La fundación de Santa Fe (1491-1520). Granada, 1995. p. 334. 
tura, sin embargo, no es mucho mayor que la del resto de las casas, que tienen todas cubierta de teja a dos aguas (L). Cabría suponer que durante la construcción de la ciudad se levantó una iglesia provisional, pues en las cuentas del tesorero real Gonzalo de Baeza, referidas al $20 \mathrm{de}$ diciembre de 1491, podemos leer «Por otra çedula de su Alteza, firmada y asentada, fecha al dicho dia, a Alonso lobo, capellan, 4.000 mrs., para la ofrenda de la misa nueva, que el canto en la yglesia de Santa $\mathrm{Fe}{ }^{50}$. Esta iglesia primigenia, cuya única alusión gráfica conservada es la que de ella se hace en este tablero, debió de preceder a la que hasta la fecha se suponía que fuese la primera. Una segunda iglesia comenzaría a erigirse tras el rescripto Papal del 21 de mayo de 1492, teniendo lugar en ella su primera fundación de misas en 1503, debidas al primer arzobispo de Granada Fray Hernando de Talavera. Por otra parte, sabemos que en 1542 ésta última todavía estaba en construcción, dado que el 22 de mayo de ese año un morisco alfarero suscribe lo siguiente: «(...) yo, Lorenço el Valorí, vecino de Gaviar la Grande, alquería de la çibdad de Granada, otorgo e conozco que me obligo de traer y entregar a vos Andrés Moro, mayordomo de la Yglesia de Santa Fee, que soys presente, seys mill ladrillos de resylla que sean muy buenos, a contento de Salas, ofiçial que agora labra en la dicha Yglesia (...)» ${ }^{51}$. Desapareció en el último cuarto del siglo xvIII por los problemas de estabilidad que presentaba, dejando paso a la Iglesia Colegial que hoy se conserva, edificada siguiendo el proyecto de Ventura Rodríguez, Ingeniero y Maestro Mayor de Obras Reales ${ }^{52}$.

En el tablero que estamos analizando, junto a la casa que está frente a la iglesia, sobresale un ancho torreón con antepechos ciegos que no presentan almenas (M). En el único plano conservado de la Casa Real de Santa Fe correspondiente a la planta baja (Fig. 15), que fue localizado en el Archivo General de Simancas por $\mathrm{M}^{\mathrm{a}}$ Amparo Moreno Trujillo y Rafael López Guzmán ${ }^{53}$, podemos distinguir una amplia zona cuadrangular que bien podría ser un torreón $(\mathrm{N})$, si la desligamos de un añadido al oeste y de otro gran núcleo rectangular al sur, correspondiente a una casa con patio a la que se adosa ${ }^{54}$. Por otra parte, en el memorial presentado en 1560 por Francisco de Paz, Alcaide de Santa Fe, sobre lo que quedaba por hacer en la Casa Real tras las obras iniciadas a fines de 1554 , se dice que «(...) aze de almenar toda la pared de puerta questá frontero de las casas de Cabildo (...)» ${ }^{55}$, por lo que en 1491, ésta no debía de contar con almenas. Con estos datos, creemos identificar este elemento que aparece en el tablero como parte integrante de la Casa Real.

Cercano a la puerta que se correspondería con la de Loja (puerta occidental de Santa Fe), casi pegado al arranque derecho del arco carpanel, aparece un árbol que soporta otra campana (Fig. 16), con la cuerda enrollada al tronco. No sabemos con certeza a qué puede aludir este detalle; quizás pudiese estar relacionado con la poética tradición santafesina relativa al Fresno existente en el pago que aún conserva ese mismo nombre, al que la reina Isabel se encaramaba

\footnotetext{
${ }^{50}$ De la Torre, Antonio. Cuentas de Gonzalo de Baeza, tesorero de Isabel la Católica. Madrid, 1955. Tomo I: 14771491. p. 411.

${ }^{51}$ Archivo del Ilustre Colegio Notarial de Granada. Sala II. Santa Fe. Protocolo de Francisco de Orantes, vol. II. Fol. 226r/v[48r/v]. Número de Catálogo: 50. Documento recogido por Moreno Trujillo, María Amparo. La ciudad de Santa Fe en el siglo Xvi. Documentos para su historia. Granada, 1993. p. 207.

${ }^{52}$ Lapresa Molina, Eladio. Santafe: Historia de una ciudad del siglo XV. Granada, 1979. pp. 54-55.

${ }_{53}$ Moreno Trujillo, Ma Amparo y López Guzmán, Rafael. «La Casa Real de Santa Fe». Escuela de Maestros. Revista de la U.E. de Magisterio. Granada, 1983-84. Núm. 3, pp. 196-201.

${ }^{54}$ No será en este artículo donde tratemos el posible origen de la Casa Real de Santa Fe como almunia nazarí existente en el pago del Gozco, en la que los Reyes Católicos mantienen una parte y adosan nuevas construcciones. Nótese el parecido con Darabenaz, antigua almunia real situada en el camino de Granada a la Zubia, a la que el Marqués del Cenete añade otras dependencias, entre ellas, un torreón. (Veáse Orihuela Uzal, Antonio. Casas y palacios nazaríes. Siglos XIII-XV. Barcelona, 1996. pp. 345-356).

${ }^{55}$ Archivo de la Alhambra. Leg. 15. Cédula sobre las obras de la Casa Real de Santa Fee (1554-1560). Documento recogido por Lapresa Molina, Eladio. Santafe: Historia de una ciudad del siglo xv. Granada, 1979. pp. 47 y 52.
}

$A E A$, LXXVII, 2004, 307, pp. 247 a 266 


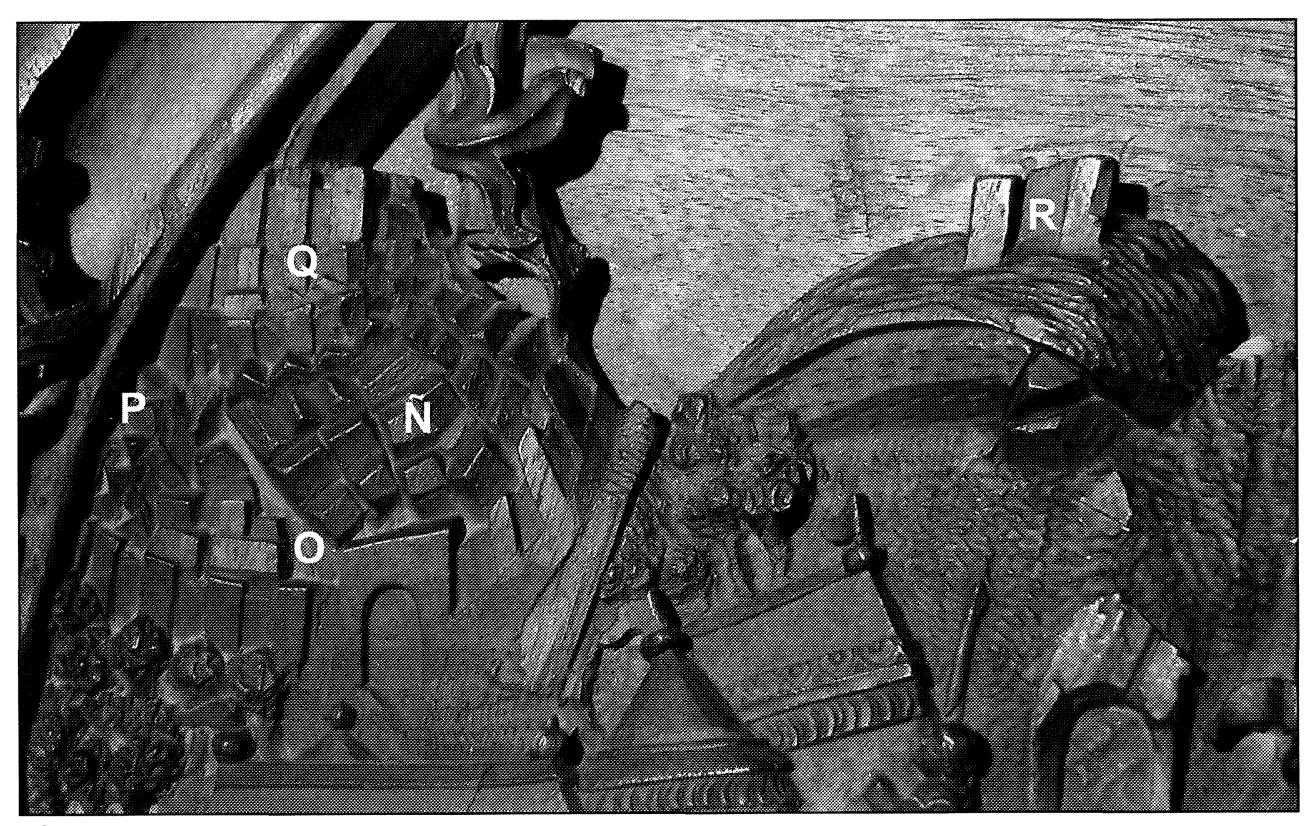

18

19

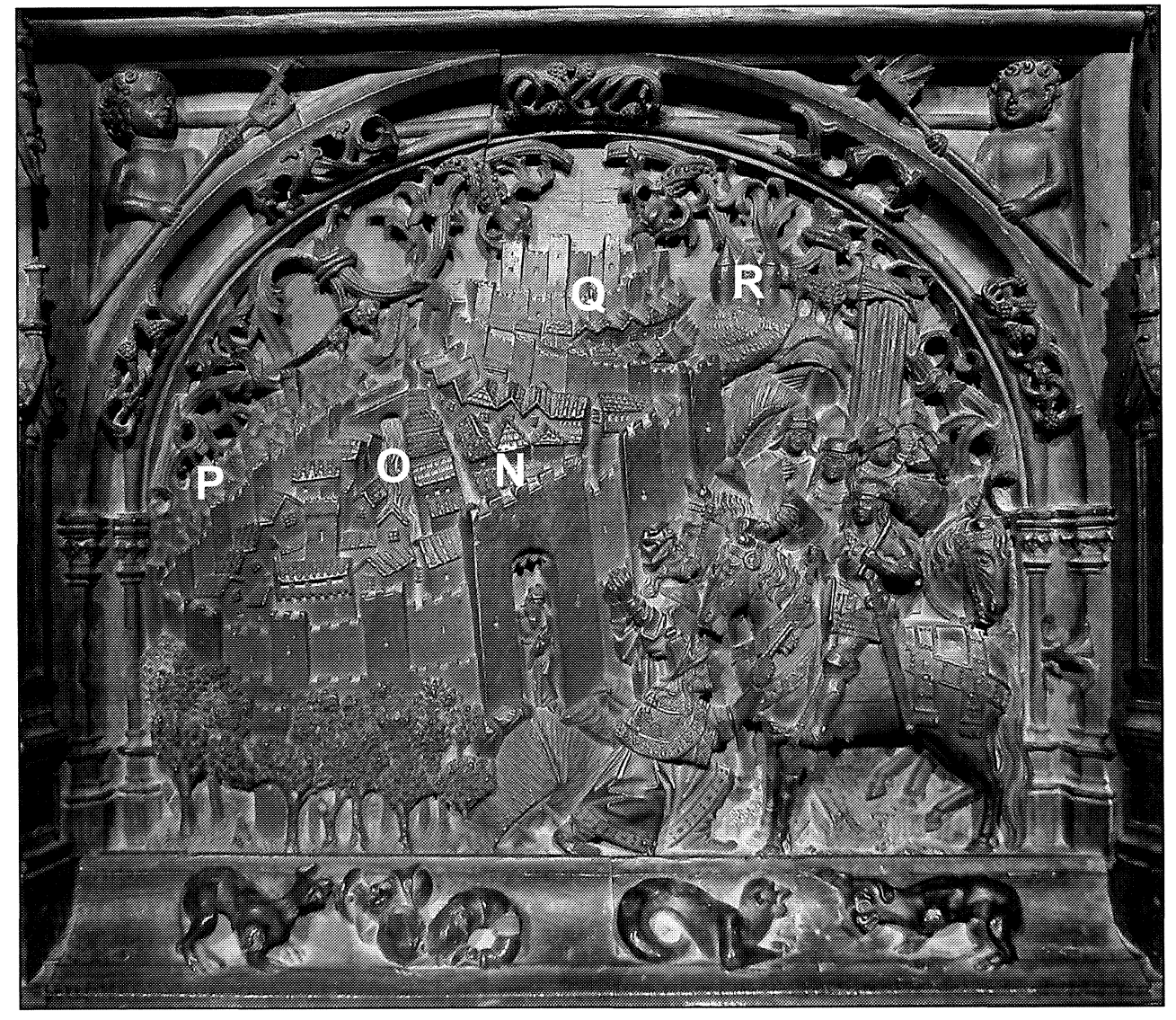

Fig. 18. Detalle de la ciudad de Granada (izquierda) y sus contornos en el tablero de la sillería del coro bajo de la Catedral de Toledo en el que se representó Santa Fe.

Fig. 19. Tablero de la sillería del coro bajo de la Catedral de Toledo donde se representa la rendición de Granada. 
para contemplar Granada ${ }^{56}$. Debajo de este detalle aparece un ajusticiado con vestimenta islámica que pende de una horca (Fig. 17). Tampoco tenemos referencias explícitas a qué pueda referirse esta macabra escenificación, pero por el hecho de aparecer junto a él otro musulmán que conduce un burro cargado con dos alforjas ${ }^{57}$, podría estar relacionado con los saqueos que hicieron los cristianos en las alquerías cercanas, pues como un anónimo musulmán relata «Continuando su obra de destrucción demolió [Fernando el Católico] varias alquerías, disponiendo que sus materiales fuesen transportados en carretas á la ciudad que estaba edificando, cuya construcción él mismo inspeccionaba» ${ }^{58}$.

\subsection{La ciudad de Granada}

Al fondo aparece la ciudad de Granada (Fig. 18), rodeada de árboles y defendida por una muralla torreada, con antemuralla. En el interior se distinguen tres recintos que corresponden a la Medina $(\tilde{\mathrm{N}})$ atravesada por el río Darro $(\mathrm{O})$, al Albaizín $(\mathrm{P})$ — separado del anterior por una muralla - y a la ciudadela palatina de la Alhambra $(\mathrm{Q})$, con sus distintos paños de muralla y las altas torres de su Alcazaba. A la derecha, sobre un monte parecen verse unas torres que podrían pertenecer al ruinoso Palacio de los Alijares (R), muy dañado por los terremotos acaecidos en el mes de julio de $1431{ }^{59}$. Para poder contemplar con más detalle todos estos elementos, junto a otros (mezquita mayor, ajimeces en las casas...), habría que remitirse al tablero que tiene por tema la rendición de Granada (Fig. 19), en el que esta ciudad es la verdadera protagonista, ocupando dos terceras partes del mismo.

\footnotetext{
${ }^{56}$ Espinosa Cabezas, Ángel. Santa Fe. Aproximaciones geográfico-históricas. Maracena (Granada), 1995. p. 58.

${ }^{57}$ Motivo éste que sí es común en otros tableros de la serie y que representa la huida de campesinos de las zonas de cultivo para entrar en las ciudades fortificadas.

${ }^{58}$ de Eguilaz y Yánguas, Leopoldo. Reseña histórica de la conquista del Reino de Granada por los Reyes Católicos según los cronistas árabes. Granada, 1894. p. 47.

${ }^{59}$ Espinar Moreno, Manuel y Quesada López, J.J. «Precisiones a las campañas de Juan II contra el reino de Granada». Homenaje al Pr. José María Fórneas Besteiro. Granada, 1995. pp. 735-775.
} 